\title{
Inequality in Life and Death
}

\section{Martin S. Eichenbaum ${ }^{1}$ - Sergio Rebelo ${ }^{2}$ - Mathias Trabandt ${ }^{3,4}$}

Published online: 29 September 2021

(C) International Monetary Fund 2021

\begin{abstract}
We argue that the COVID epidemic disproportionately affected the economic wellbeing and health of poor people. To disentangle the forces that generated this outcome, we construct a model that is consistent with the heterogeneous impact of the COVID recession on low- and high-income people. According to our model, twothirds of the inequality in COVID deaths reflect preexisting inequality in comorbidity rates and access to quality health care. The remaining third stems from the fact that low-income people work in occupations where the risk of infection is high. Our model also implies that the rise in income inequality generated by the COVID epidemic reflects the nature of the goods that low-income people produce. Finally, we assess the health-income trade-offs associated with fiscal transfers to the poor and mandatory containment policies.
\end{abstract}

Keywords Epidemic $\cdot$ Inequality $\cdot$ Recession

JEL Classification $\mathrm{E} 1 \cdot \mathrm{I} 1 \cdot \mathrm{H} 0$

We thank Laura Murphy and Federico Puglisi for excellent research assistance.

Replication codes are available on the authors' websites.

Sergio Rebelo

s-rebelo@kellogg.northwestern.edu

Martin S. Eichenbaum

eich@northwestern.edu

Mathias Trabandt

mathias.trabandt@gmail.com

1 Department of Economics, Northwestern University and NBER, 2211 Campus Dr, Evanston, IL 60208, USA

2 Kellogg School of Management, Northwestern University, NBER, and CEPR, 2211 Campus Dr, Evanston, IL 60208, USA

3 Goethe University Frankfurt, Theodor-W.-Adorno-Platz 3, 60323 Frankfurt am Main, Germany

4 Halle Institute for Economic Research (IWH), Halle, Germany 


\section{Introduction}

It is widely believed that the COVID epidemic disproportionately affected the economic well-being and health of poor people. Authors like Chetty et al. (2020) show that during the COVID recession employment fell the most for low-income workers. We show that there is a strong, robust correlation between pre-COVID measures of income inequality and COVID deaths across US states. This relation holds even when we control for differences in demography and access to health care. Taken together, these findings support the view that the COVID epidemic created more inequality in life and death.

To interpret these statistical findings, we develop a quantitative model of the COVID epidemic. The model articulates a simple mechanism by which COVID exacerbated preexisting inequality in income and health. The basic idea is that lowwage workers are disproportionately employed in occupations that require a high level of social contact, making them susceptible to becoming infected. The demand for the types of goods produced by these workers fell dramatically relative to the goods produced by high-income workers. The net effect was that many low-wage workers lost their job. Those who retained their job were more likely to become infected than high-wage workers. An exacerbating factor is that low-wage workers, at least in the USA, have more limited access to high-quality health care than high-wage workers. In our model, these forces generate the strong, positive relation between ex-ante income inequality and COVID deaths observed in the data.

A key challenge in designing our model is the requirement that it be consistent with the fact, documented by Chetty et al. (2020), that low-income workers suffered larger drops in employment than high-income workers but expenditures by low-income workers fell by less than those of high-income workers. This task is challenging because conventional business cycle models generally embody strong consumption smoothing behavior. ${ }^{1}$

The reason our model can account for these facts is as follows. The behavior of high-income people is governed by two key considerations. First, they are much less prone to becoming infected at work than low-income people. Second, they have a higher lifetime utility than low-income people which makes them more sensitive to the dangers of becoming infected through market activity. In conjunction with our other assumptions, these considerations imply that employment falls by less for high-income people than for low-income people. But high-income people cut their consumption by more than low-income people.

The behavior of low-income people is governed by the following considerations. Consistent with the data, we assume that the goods produced by low-income people are more infectious that those produced by high-income people. So, the decline in consumption demand is concentrated in sectors that employ low-income people. As a result, the employment of low-income people falls disproportionately. Lowincome people are closer to the subsistence level of consumption, so they reduce their

\footnotetext{
1 A potentially important exception are business cycle models with wealthy hand-to-mouth consumers of the type emphasized by Kaplan et al. (2014).
} 
consumption by less than high-income people. Moreover, consistent with the data, low-income people receive government transfers during the pandemic. Taken together, these forces imply that the employment of low-income people falls by more than that of high-income people, but their consumption falls by less.

To articulate these mechanisms in a transparent way, we focus our analysis on the first wave of the epidemic (from March to July 2020). After the first wave, expectations about possible vaccinations and changes in fiscal policy associated with the presidential election arguably played a larger role in affecting people's behavior. By focusing on the first wave, we are able to abstract from these complications.

We show that our model is consistent with three key features of the data. First, it accounts reasonably well for COVID deaths during the first wave. Second, it accounts for the facts document by Chetty et al. (2020). Third, it accounts for the strong statistical relation between pre-COVID income inequality and COVID deaths that we document.

We then turn to the question: How was inequality in life and death during the first wave of the epidemic affected by containment policies and government transfers to low-income people? According to our model, containment disproportionately reduced the employment and income of low-income workers, magnifying income disparities. Containment also dramatically reduced mortality rates for all income groups. Evidently, containment policies involve sharp trade-offs between health and income inequality.

Turning to fiscal policy, we find that government transfers during the first wave of the epidemic increased employment and income of low-income workers, reducing income inequality. But it did not substantially increase the death toll from the epidemic. So, in the context of the COVID epidemic, government transfers do not involve sharp trade-offs between health and income inequality.

To focus our analysis, we abstract from three important issues that have received extensive attention in the literature. The first is the impact of ethnicity and racial background per se on COVID infections and death (see, e.g., Benitez et al. 2020 Desmet and Wacziarg (2020) and McLaren 2020). The second is the impact of the COVID recession on gender equality (see, e.g., Alon et al. 2020; Jin et al. 2020). The third is the differential impact of COVID on young and old (see, e.g., Acemoglu et al. 2020; Brotherhood et al. 2020; Eichenbaum et al. 2020; Giagheddu and Papetti 2020 and Glover et al. 2020).

The paper is organized as follows. Section 2 briefly reviews the economics literature on the impact of the epidemic in models with heterogeneity. Section 3 contains the empirical evidence we use as the background for our analysis. Section 4 describes the model. Section 5 discusses the quantitative properties of our model and its implications for the impact of containment measures and fiscal transfers. Section 6 concludes.

\section{Related Literature}

There is by now a large literature on the macroeconomic impact of epidemics. Examples include Acemoglu et al. (2020), Alvarez et al. (2021), Brotherhood et al. (2020), Buera et al. (2020), Faria-e-Castro (2020), Farboodi et al. (2020), 
Gonzalez-Eiras and Niepelt (2020), Krueger et al. (2020), Jones, Philippon, and Venkateswaran (2020), Guerrieri et al. (2020), Piguillem and Shi (2020) and Toxvaerd (2020). We do not attempt to survey this literature here. Instead, we discuss the papers most closely related to ours.

In this paper, we build on our prior work which features an explicit two-way interaction between epidemic and economic dynamics (Eichenbaum et al. 2021). The epidemic creates a recession because people cut back on their economic activities to reduce the probability of being infected. At the same time, the recession reduces the rate at which the virus spreads throughout the population.

Our model is closely related to the work of Kaplan et al. (2020). These authors study epidemics in a model where people are heterogeneous along a variety of dimensions. Two key forms of heterogeneity in their environment are differences in the probability of becoming infected at work and the extent to which liquidity constraints are binding. We view our results as complementary to theirs. Our contribution is twofold. First, we emphasize the importance of preexisting inequality in case fatality rates between high- and low-income people. Second, we highlight in a simple setting the key forces that generate the observed unequal health and economic consequences of the epidemic.

Glover et al. (2020) analyze a two-sector model (essential and luxury) with young workers and retirees. The epidemic creates important distributional effects because the luxury sector contracts by more than the essential sector. In addition, containment measures redistribute welfare from the young to the old. The old benefit from the reduced risk of infection produced by containment, while the young suffer the adverse employment consequences. Carnap et al. (2020) explore how optimal containment policy varies across countries, depending on demographic factors, the prevalence of comorbidities and the strength of the health-care system. Rubini (2020) studies a model with a subsistence level of consumption and heterogeneous work-at-home possibilities. These elements generate substantial heterogeneity in the impact of the epidemic across countries. Crucini and O'Flaherty (2020) emphasize the importance of regional heterogeneity in epidemic dynamics. In their model, each location initially experiences an idiosyncratic virus shock. The virus then spreads within locations, through both consumption and employment activities. It also spreads across locations through travel. Engler, Pouokam, Guzman, and Yakadina (2020) analyze the interactions between inequality and the epidemic in an open economy context.

Finally, there is a large literature relating the empirical relation of socioeconomic status to the incidence of COVID and health outcomes. Below, we discuss three key findings that provide independent support for the mechanisms at work in our model.

First, there is strong evidence that the COVID case fatality rate is substantially higher for poor people. Chen and Krieger (2020) and Krieger et al. (2020) find that, in the USA, case fatality rates are higher in lower-income counties and zip codes. While useful, those studies do not link individual incomes to health outcomes. Drefahl et al. (2020) overcome this limitation. These authors use data that link all recorded COVID deaths in Sweden to highly accurate individual-level administrative data. They find a sharp, negative correlation between case fatality rates and income levels. 
Second, the probability of dying from COVID is highly correlated with comorbidity conditions and lack of access to high-quality health care. The Center for Disease Control and Prevention (2020) provides a thorough review of the comorbidities that increase the risk of severe illness and death from COVID. There is substantial evidence that the relevant comorbidities are negatively related to income, see, for example, Hosseinpoor et al. (2012); Price-Haywood et al. (2020); Raifman and Raifman (2020); and Williamson et al. (2020).

Third, there is substantial evidence that high-contact industries disproportionately employ low-skill, low-wage workers. Other studies provide evidence that high-contact industries disproportionately employ low-skill, low-wage workers. For example, Leibovici, Santacreu and Famiglietti (2020) combine individual-level data from the 2017 American Community Survey with the O*NET index of occupational contact intensity. These authors show that the workers in high-contact occupations have on average lower incomes. The fact that infections through work are much more likely for low-income than for high-income people is consistent with evidence in Dingel and Neiman (2020). Finally, Kaplan et al. (2020) provide microevidence that lowincome people work in occupations that are more contact intensive than those of high-income people.

\section{Empirical Evidence}

In this section, we provide the empirical background for our analysis. First, we present cross-sectional evidence from the USA on the relation between preexisting income inequality and COVID deaths. Second, we display the time series for consumption expenditures and employment by income groups in the USA using data provided by Chetty et al. (2020).

A successful theory of the relation between inequality and COVID deaths needs to be consistent with both the cross-sectional and the time series evidence. As it turns out, the latter evidence plays a crucial role in disciplining the way we model the forces governing the interaction between the COVID epidemic and income inequality.

\subsection{Cross-Sectional Correlations}

We begin by discussing our data sources. The number of COVID deaths per million is from the Centers for Disease Control and Prevention. The Gini coefficient is from the 2019 Census Bureau's American Community Survey. Data on real personal income per capita (purchasing power parity adjusted) are from the Bureau of Economic Analysis for 2019, quarter 4. Data on the fraction of the population aged 65 or older are from the 2019 Census Bureau's American Community Survey. Data on the share of the population in urban areas are from the 2010 Census. Data on the number of physicians per one thousand people are from the American Association of Medical Colleges.

Our analysis is conducted using cross-sectional data for states in the USA. We consider two samples both of which begin on January 22, 2020. The full-sample 


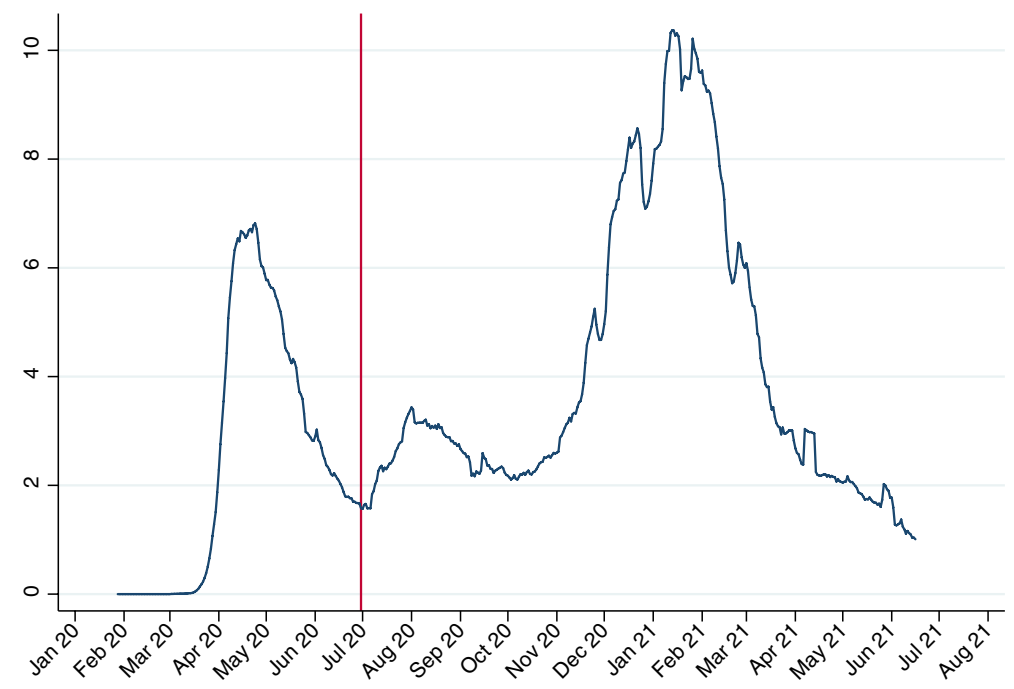

Fig. 1 New deaths per million Note: 7-day moving average is displayed

Table 1 Data: summary statistics

Panel A: predetermined variables

\begin{tabular}{lll} 
Levels & & Percent Logs \\
\hline Meant $^{\dagger}$ & Standard $^{\dagger \dagger}$ & Standard \\
& Error & Deviation
\end{tabular}

\begin{tabular}{llll}
\hline Gini coefficient & 46.3 & 0.3 & 4.1 \\
Real Income per capita & 50387.7 & 770.1 & 11 \\
(PPP adjusted) & & & \\
65 or older, share of pop & 16.9 & 0.3 & 12.7 \\
Urban share & 73.8 & 2.1 & 22 \\
Physicians per 1000 & 2.8 & 0.1 & 25 \\
\hline
\end{tabular}

Panel B: Dependent variable, cumulative deaths per million

\begin{tabular}{lll} 
Meant $^{\dagger}$ & $\begin{array}{ll}\text { Standard }^{\dagger \dagger} & \text { Standard }^{\dagger \dagger} \\
\text { Error } & \text { Deviation }\end{array}$ \\
\hline
\end{tabular}

Full sample

(01/22/2020-06/13/2021)

1658.7

85.5

76

First-wave sample

(01/22/2020-06/30/2020)

308.68

48.8

108

${ }^{\dagger}$ Means pertain to the level of the variables

${ }^{\dagger}$ Standard errors pertain to estimates of the mean

${ }^{\dagger}$ Standard deviations pertain to the distribution of the $\log$ of the variable, across states, expressed in percentage points

Data sources are discussed in the main text 
period ends on June 13, 2021 while the "first-wave" sample period ends on June 30, 2020. Figure 1 displays new deaths per million in the USA over the full-sample period, with the red vertical line drawn at the end of the first-wave sample. Table 1 reports the average levels of the variables used in our empirical analysis, as well as their standard deviations. By construction, the right-hand side variables in the regressions are the same in the two sample periods. Note that total deaths per million is roughly five times higher in the full sample than in the first-wave sample. For both sample periods, there is a great deal of cross-sectional variability in total deaths per million across US states. For the first-wave sample the standard deviation of the logarithm of deaths per million is roughly 108 percent. The corresponding figure for the full sample is 76 percent.

Table 2 presents our empirical results. All independent variables are measured prior to the onset of the COVID epidemic. Three results are worth noting. First, the Gini coefficient is statistically significant at the one-percent significance level for both sample periods. A one standard deviation increase in the Gini coefficient increases the number of COVID deaths per million by 31 and 52 percent, in the full- and first-wave sample, respectively.

Second, for the full sample, physicians per 1000 people are statistically significant at the one-percent level. The fraction of the population 65 and older and the level of real personal income per capita are significant at the 5 percent level.

Table 2 Baseline regressions for US States

\begin{tabular}{lll}
\hline Dependent variable: Log of cumulative deaths per million & \\
\hline & $(1)$ & $(2)$ \\
& Jan '20-Jun '21 & Jan '20-Jun '20 \\
\hline Gini coefficient & $7.67^{* * *}$ & $12.76^{* * *}$ \\
& $(1.47)$ & $(3.54)$ \\
Real personal income & $1.70^{* *}$ & 2.61 \\
& $(0.79)$ & $(1.67)$ \\
65 or older pop share & $0.86^{* *}$ & 1.27 \\
& $(0.43)$ & $(1.16)$ \\
Urban share & 0.44 & 1.15 \\
& $(0.35)$ & $(0.75)$ \\
Physicians per 1000 & $-1.07^{* * *}$ & 0.31 \\
Constant & $(0.28)$ & $(0.67)$ \\
Observations & $-43.71^{* * *}$ & $-80.75^{* * *}$ \\
R-squared & $(11.86)$ & $(23.39)$ \\
\end{tabular}

Robust standard errors in parentheses

$* * * \mathrm{p}<0.01, * * \mathrm{p}<0.05, * \mathrm{p}<0.1$

All variables included in the regression are in logs. Sources are outlined in the main text. Summary statistics are provided in Table 1. Robust Standard Errors are reported in parentheses. Real personal income is in per capita terms 
A more elderly population and higher real personal income per capita are associated with more COVID deaths. Presumably the latter result reflects that a higher her per capita GDP is associated with more trade, commerce and social interactions. As expected, a higher number of physicians per 1000 is associated with fewer deaths from COVID. In contrast, for the first-wave sample, the only statistically significant variable in the regression is the Gini coefficient. Of course, the fact that certain right-hand side variables are not statistically significant variables could reflect multicollinearity issues. ${ }^{2}$

The key takeaway from Table 2 is that pre-epidemic income inequality is a robust explanatory variable for COVID deaths. A different way to see the strong statistical relation between these variables is a scatter diagram. The first column of Panels A and B in Fig. 2 presents scatter diagrams of the logarithm of the Gini coefficient and the logarithm of COVID deaths per million in the two samples. The raw correlation between these variables is 0.56 and 0.57 in the full- and first-wave sample, respectively. The second column of Panels A and B in Fig. 2 shows the partial correlation between the Gini coefficient and COVID deaths per million based on the controls included in Table 2. The correlation between these variables is 0.67 and 0.53 in the full- and the first-wave sample, respectively.

In sum, there is a strong and clear statistical relationship between preexisting inequality and COVID deaths across US states.

\subsection{US Employment and Consumption Expenditures During the COVID Recession}

In this subsection, we review three important findings documented by Chetty et al. (2020).

Figure 3 displays weekly US employment and consumption expenditures, relative to January 4-31, 2020, for three income groups. Panel A displays consumption expenditures for people in ZIP codes with low (bottom quartile) median (two middle quartiles) and high income (top quartile). Panel B displays employment levels for workers with low (bottom quartile) median (two middle quartiles) and high income (top quartile). Our sample period is January 14 to May 30, 2021. The data are aggregated to a weekly frequency from daily data provided by Chetty et al. (2020).

Six features emerge from Fig. 3. First, employment and consumption expenditures fell for all groups in the beginning of the crisis and then recovered during the summer. Second, employment fell the most for workers in the bottom quartile of the income distribution, with a peak-to-trough decline of roughly 37 percent in the first wave of the epidemic. The analogue decline for workers in the top-income quartile was only 13 percent. Third, consumption expenditures fell the most for people in high-income ZIP codes, with a peak-to-trough decline of 34 percent. The analogue decline for consumers in low-income ZIP codes is 26 percent. Fourth, consumption expenditures of low-income people recover more quickly than those of high-income people. Five, the percentage decline in employment

\footnotetext{
${ }^{2}$ Our first-wave and full-sample results are robust to including other variables, like average winter temperature, in the regression.
} 
Panel A: Full Sample Period Jan '20 - Jun '21

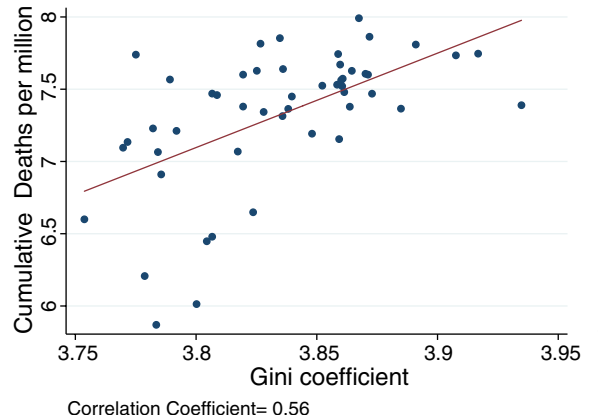

(a) Raw Correlation

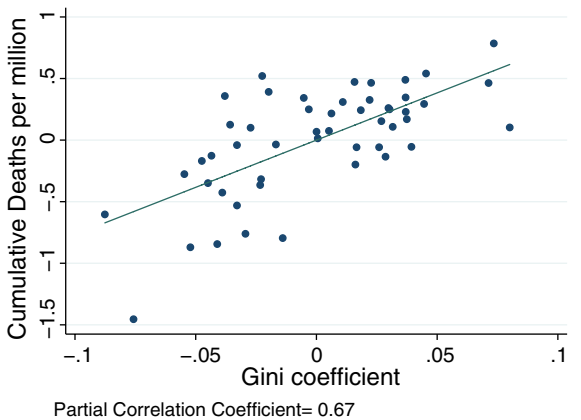

(b) Partial Correlation

Panel B: First Wave Sample Period Jan '20 - Jun '20

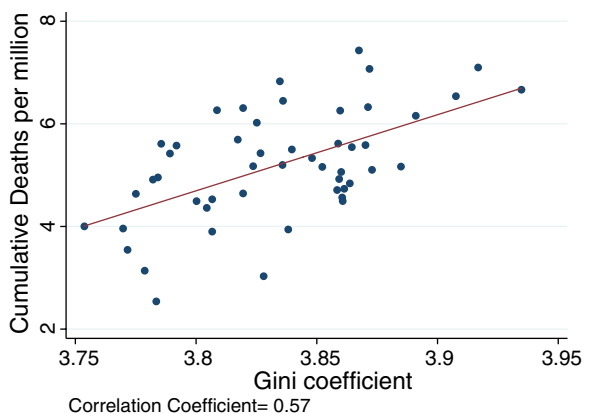

(c) Raw Correlation

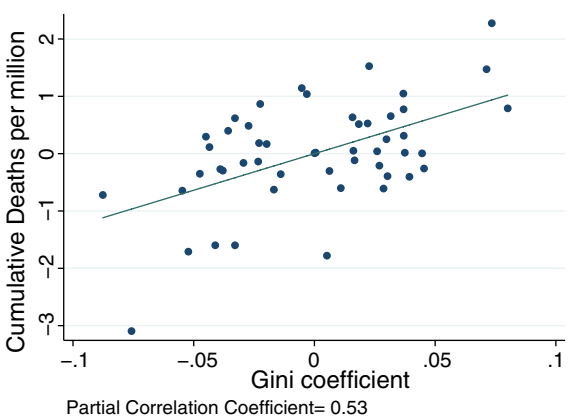

(d) Partial Correlation

Fig. 2 Raw and Partial Correlations

for high-income workers was much smaller than the percentage decline in consumption expenditures. So, for this group income was smoother than consumption. Sixth, the extent to which employment recovered varies by income group. At the end of the sample employment of high-income people actually exceeded its pre-COVID level. For middle-income people, employment recovered to 2 percent below its pre-COVID level. In sharp contrast, employment of low-income people recovered after the first wave but substantially declined again during the second wave that began roughly in December of 2020.

The spending patterns documented by Chetty et al. (2020) have been corroborated by other authors using data for the USA (Cox et al. 2020), the UK (Hacioglu et al. 2020), Spain (Carvalho et al. 2020) and Portugal (Eichenbaum et al. 2020), respectively. 

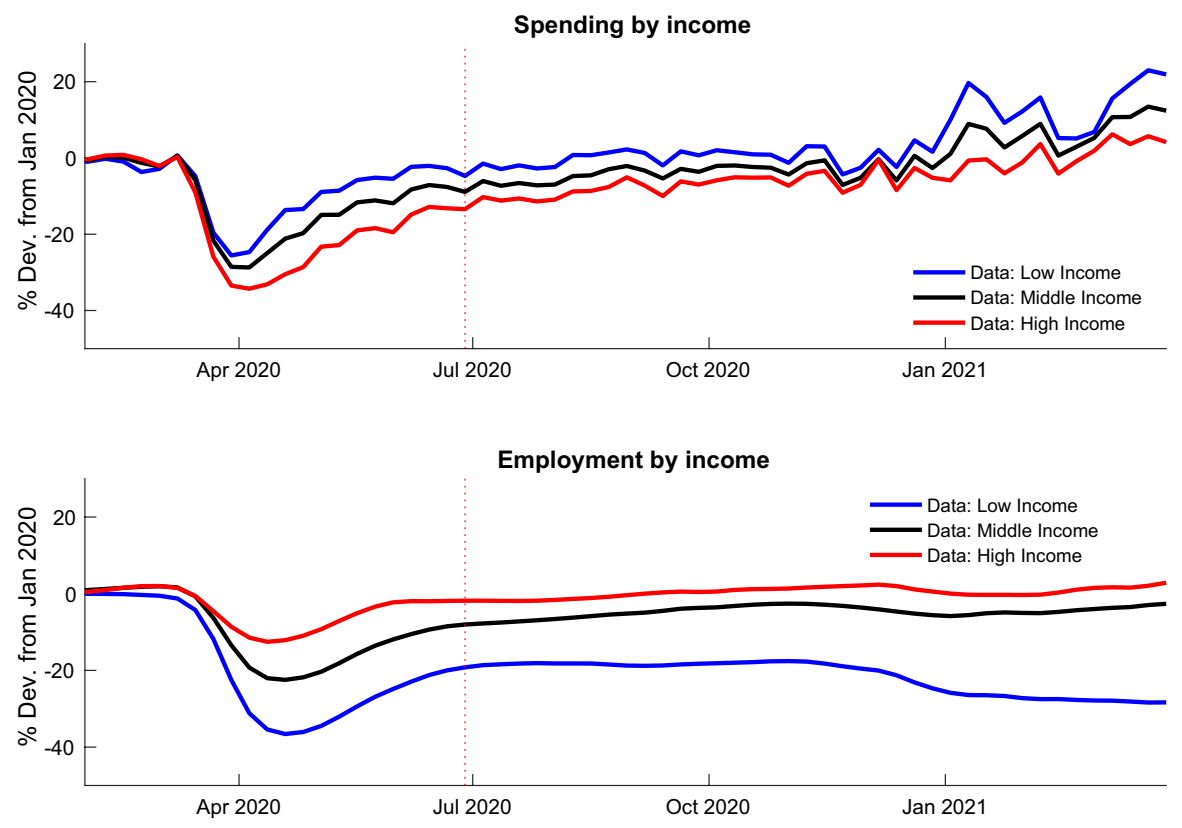

Fig. 3 Spending and Employment by Income

\section{Model}

Our model is designed to articulate a simple mechanism by which COVID exacerbated preexisting inequality in income and health. The basic idea is that lowwage workers are disproportionately employed in occupations that require a high level of social contact, making them susceptible to COVID. The demand for the types of goods produced by these workers fell dramatically relative to the goods produced by high-income workers. The net effect was that many low-wage workers lost their job while those that retained their job were susceptible of becoming infected. An exacerbating factor is that low-wage workers, at least in the USA, have more limited access to high-quality health care than high-wage workers. Taken together, these forces can generate the empirical relation between ex-ante inequality and the disproportionate health and economic impact of COVID on low-wage workers.

A key challenge in modeling this mechanism is the requirement that the model be consistent with the Chetty et al. (2020) facts: low-income workers suffered larger drops in employment than high-income workers but expenditures by low-income workers fell by less than those of high-income workers. It turns out that these observations are an important discipline on our model. To make clear the essential features necessary to account for both the Chetty et al. (2020) and the inequality facts, we focus on two types of workers as opposed to the richer specification considered in Kaplan et al. (2020). For ease of exposition, we refer to low- and high-income workers as being occupied in the nontradable and tradable goods sectors, respectively. 
In principle, it would be straightforward to have a closed-economy version of the model in which all the goods have to be produced domestically. Using a small open economy lets us highlight the mechanisms at work in our model with a minimum of complications.

We assume that the nontradable good is associated with higher infection risk than the tradable good, in both production and consumption. Our motivation is as follows: Ross and Bateman (2019) show that low-wage workers are concentrated in sectors such as retail sales, food and beverage service, cooks and food preparation, and other personal care and service workers. These sectors are generally thought of as producing nontradable goods and services. Dingel and Neiman (2020) use the O*NET database to show that most of these jobs cannot be performed from home. So workers in these industries must maintain high levels of social contact that increase the chances of becoming infected. Broadly speaking, we think of these workers as having occupations in sectors that Kaplan et al. (2020) classify as "essential" or "social-rigid" that is sectors with a high degree of social interaction and jobs that cannot be performed from home. Significantly, Abel and Deitz (2021) show that, regardless of occupation, lowwage workers are less likely to work remotely.

To generate income inequality in the model, we make the following assumptions. First, people are specialized in the type of goods that they can produce. Second, there is a relatively large supply of people who can produce the nontradable good. As a result of these two assumptions, wages are much higher in the tradable goods sector than in the nontradable goods sector. The model abstracts from income heterogeneity of workers within each sector.

We assume that low-income people are "hand-to-mouth" consumers. This assumption is consistent with evidence in Kaplan et al. (2020) that there is a high share of hand-to-mouth consumers in the "essential" or "social-rigid" sectors. The government and high-income people can borrow and lend in international capital markets.

To simplify the analysis, we assume that the real interest rate is fixed. In practice, the US real interest rate as measured by 10 -year Treasury inflation-indexed bonds fell by roughly one percent after March 2020. This fall reflected a host of considerations including an initial flight to safety and the response of monetary policy to the pandemic. Modeling these effects would greatly complicate the analysis without changing our central message.

Finally, for tractability, we assume that people are organized into high- and lowincome households, each of which has a continuum of identical members. This household structure introduces limited sharing of health risks among people with the same income. Without the household structure, the asset holdings of a person would depend on how long they had a particular health status. So, as time goes by, we would have to keep track of an increasing number of types of people.

\subsection{Tradable and Nontradable Consumption Goods}

The price of the nontradable good, $P_{1 t}$, is determined in the domestic market. The price of the tradable good, $P_{2 t}$, is determined in international markets by absolute purchasing power parity: 


$$
P_{2 t}=X_{t} P_{t}^{*}
$$

Here, $P_{t}^{*}$ is the price of the tradable good in foreign currency and $X_{t}$ is the nominal exchange rate, expressed as units of domestic currency per unit of foreign currency. To simplify, we normalize $X_{t}$ and $P_{t}^{*}$ to one, so

$$
P_{2 t}=1 \text {. }
$$

There is a measure-one continuum of competitive tradable and nontradable good firms. Production of the nontradable good $\left(Y_{1 t}\right)$ is given by:

$$
Y_{1 t}=A_{l} N_{l t}
$$

Production of the tradable good $\left(Y_{2 t}\right)$ is given by:

$$
Y_{2 t}=A_{h} N_{h t} .
$$

The variables $N_{l t}$ and $N_{h t}$ denote the amount of labor used in the production of nontradable and tradable goods, respectively.

The profits of nontradable and tradable goods producers are

$$
\begin{aligned}
& \psi_{1 t}=P_{1 t} A_{l} N_{l t}-w_{l t} N_{l t}, \\
& \psi_{2 t}=P_{2 t} A_{h} N_{h t}-w_{h t} N_{h t},
\end{aligned}
$$

where $w_{l t}$ and $w_{h t}$ are the wages of workers in the nontradable and tradable sector, respectively. Since people can only work in one sector, $w_{l t}$ is, in general, not equal to $w_{h t}$.

Firms' first-order conditions are

$$
\begin{gathered}
w_{l t}=P_{1 t} A_{l}, \\
w_{h t}=P_{2 t} A_{h} .
\end{gathered}
$$

Since firm profits are zero in equilibrium with both flexible and sticky wages, it does not matter who owns the firms.

\subsection{Sticky Wages}

To prevent large counterfactual swings in the relative price of nontradables, we incorporate nominal rigidities in the model. We assume that wages are sticky and equal to their pre-epidemic levels. According to Eq. (2), sticky wages imply that $P_{1 t}$ is sticky. Since $P_{2 t}$ is constant, the relative price of nontradables is constant.

Our motivation is as follows. With the onset of COVID, the US dollar initially appreciated reflecting a flight to safety. That appreciation was quickly reversed and the real exchange rate remained similar to its pre-COVID value. For example, the broad trade-weighted US dollar index for goods and services was 115 in January 
2020 and 111 in May 2021. ${ }^{3}$ In our model, the real exchange rate is driven by the relative price of tradable to nontradable goods. Given our assumption, the real exchange rate is constant in our model.

Our model also implies that inflation is zero. This property captures the notion that inflation did not respond substantially to the COVID epidemic. Cavallo (2020) provides a detailed analysis of inflation during the COVID epidemic allowing for changes in expenditure weights. Some categories like "food at home" show substantial inflation. But the overall behavior of inflation was similar before and after COVID.

Our assumption that wages are sticky captures the notion that inflation did not respond substantially to the COVID epidemic. The Federal Reserve Bank of Atlanta uses microdata from the Current Population Survey to compute median wage growth of high-, medium- and low-skill workers. According to these data, for each skill category, the average monthly median wage growth in the 12 months preceding February 2020 was about the same as in the 12 months preceding February 2021. So COVID did not affect the pattern of wage growth.

From a modeling perspective, the assumption of sticky wages has no impact on the market for high-income workers. The reason is that the equilibrium value of $w_{h t}$ is constant and equal to its pre-epidemic value (see Eq. (3)). The sticky wage assumption does affect the equilibrium wages of low-income workers. As in standard in sticky wage models (e.g., Erceg et al. 2000), we assume that employment is demand determined. So, the first-order condition for hours worked does not hold for low-income people. In contrast, the first-order conditions for hours worked by highincome workers does hold.

\subsection{Epidemic Dynamics}

Before the onset of the epidemic, the economy is in steady state. We normalize the size of the initial population to one. Let $s_{h}$ and $s_{l}$ denote the share of the initial population that has high and low income, respectively. As in the classic SIR model of Kermack and McKendrick (1927), at the onset of the epidemic the population is divided into four groups: susceptible (people who have not yet been exposed to the virus), infected (people who have been infected by the virus), recovered (people who survived the infection and acquired immunity) and deceased (people who died from the infection). We denote the fraction of the initial population in each group by $S_{j t}, I_{j t}, R_{j t}$ and $D_{j t}$, respectively. The subscript $j$ refers to high $(h)$ or low skill $(l)$, $j \in\{l, h\}$.

At time zero, a fraction $\varepsilon$ of the population is infected by a virus. The initial infection is distributed across high- and low-skill workers according to the weight of these groups in the population,

$$
I_{j 0}=s_{j} \varepsilon
$$

3 Series RTWEXBGS constructed by the Board of Governors of the Federal Reserve System.

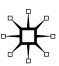


$j=l, h$. The rest of the population is susceptible to the virus,

$$
S_{j 0}=s_{j}(1-\varepsilon) \text {. }
$$

Social interactions occur at the beginning of the period (infected and susceptible people meet). Then, changes in health status unrelated to social interactions (recovery or death) occur. At the end of the period, the consequences of social interactions materialize and $\tau_{j t}$ susceptible people of type $j$ become infected.

As in Eichenbaum et al. (2021), we assume that susceptible people can become infected in three ways: purchasing consumer goods, working and through random interactions unrelated to economic activity.

The variables $\left(c_{j g t}^{s}, c_{j g t}^{i}, c_{j g t}^{r}\right)$ and $\left(n_{j t}^{s}, n_{j t}^{i}, n_{j t}^{r}\right)$ denote the consumption of good $g$ and hours worked by a person of type $j$ (high or low income) who is susceptible, infected and recovered, respectively.

Recall that a person of type $j$ belongs to a household of type $j$. The shares of people in household type $j$ who are susceptible $\left(s_{j t}\right)$, infected $\left(i_{j t}\right)$, recovered $\left(r_{j t}\right)$ and deceased $\left(d_{j t}\right)$ evolve according to

$$
\begin{gathered}
s_{j t+1}=s_{j t}-\tau_{j t}, \\
i_{j t+1}=\left(1-\pi_{j r}-\pi_{j d}\right) i_{j t}+\tau_{j t}, \\
r_{j t+1}=r_{j t}+\pi_{j r} i_{j t}, \\
d_{j t+1}=d_{j t}+\pi_{j d} i_{j t} .
\end{gathered}
$$

In every period, $t, \tau_{j t}$ people who are susceptible become infected at time $t+1$ (Eqs. (4) and (5)). A fraction $\pi_{j r}$ of type $j$ people who are infected at time $t$ become recovered at time $t+1$ (Eqs. (5) and (6)). A fraction $\pi_{j d}$ of type $j$ people who are infected at time $t$ die at time $t+1$ (Eqs. (5) and (7)).

The fraction of the initial population that is of type $j$ and becomes infected at time $t$ is

$$
\begin{aligned}
\tau_{j t}= & \left(1-\epsilon_{t}^{\tau}\right)\left[\pi_{1} s_{j t} c_{j 1 t}^{s}\left(I_{h t} C_{h 1 t}^{I}+I_{l t} C_{l 1 t}^{I}\right)+\pi_{2} s_{j t} c_{j 2 t}^{s}\left(I_{h t} C_{h 2 t}^{I}+I_{l t} C_{l 2 t}^{I}\right)\right. \\
& \left.+\pi_{j 3} s_{j t} n_{j t}^{s} I_{j t} N_{j t}^{I}+\pi_{4} s_{j t}\left(I_{h t}+I_{l t}\right)\right] .
\end{aligned}
$$

Here $C_{j 1 t}^{I}$ and $C_{j 2 t}^{I}$ is the total consumption by infected people type $j$ of good 1 and 2 , respectively. The variables $I_{h t}$ and $I_{l t}$ denote the aggregate number of high- and lowincome people who are infected, respectively.

The probability of a type $j$ person getting infected by consuming goods one and two is $\pi_{1} s_{j t} c_{j 1 t}^{s}\left(I_{h t} C_{h 1 t}^{I}+I_{l t} C_{l 1 t}^{I}\right)$ and $\pi_{2} s_{j t} c_{j 2 t}^{s}\left(I_{h t} C_{h 2 t}^{I}+I_{l t} C_{l 2 t}^{I}\right)$, respectively. The term $\pi_{j 3} s_{j t} n_{j t}^{s} I_{j t} N_{j t}^{I}$ represents the probability of a type $j$ person becoming infected at work. Equation (8) embodies the assumption that type $j$ people only interact with other type $j$ people at work. The term $\pi_{4} s_{j t}\left(I_{h t}+I_{l t}\right)$ represents the 
probability of a type $j$ person being infected due to interactions that are unrelated to consumption or work.

The term $1-\epsilon_{t}^{\tau}$ in Eq. (8) represents time variation in the probability of becoming infected. This variation comes from two sources. First, there is seasonality in rates of infection. When the weather is hot, people spend less time indoors, reducing the chances of infection. Also, it is possible that summer conditions, such as warm temperatures and abundant UV light, make it harder for the virus to propagate (see, e.g., Merow and Urban 2020). Second, businesses reorganized to reduce the probability that workers and customers will get infected. This reorganization includes home delivery of food, installation of Plexiglas dividers at retail outlets and implementation of social distancing rules and mask usage in consumption and production activities.

\subsection{Households}

High-income people can save in international bond markets at a fixed interest rate, $r^{*}$. Consistent with evidence in Kaplan et al. (2020), we assume that low-income people are "hand to mouth," i.e., their consumption and income coincide.

The nontradable good is essential in the sense that people have to consume at least $\bar{c}$ units of it. The tradable good is not essential, so there is no minimum consumption requirement.

The momentary utility function of a person with health status $x$ is given by

$$
u\left(c_{j 1 t}^{x}, c_{j 2 t}^{x}, n_{j t}^{x}\right)=m+\left(1-\epsilon_{t}^{c}\right)\left[(1-\eta) \log \left(c_{j 1 t}^{x}-\bar{c}\right)+\eta \log \left(c_{j 2 t}^{x}\right)\right]-\frac{\theta}{2}\left(n_{j t}^{x}\right)^{2},
$$

where $x$ can take the values $s, i$ and $r$, corresponding to susceptible, infected and recovered, respectively. We use the variable $\epsilon_{t}^{c}$ to model exogenous variations in consumption demand associated with containment measures imposed by the government. We discuss the motivation for this way of modeling containment in the calibration section. As in Hall and Jones (2007), momentary utility includes a constant ( $m$ ) that affects the value of life. We use this constant to ensure that lifetime utility is positive so that people prefer living to dying.

Type $j$ households maximize their lifetime utility,

$$
U_{j}=\sum_{t=0}^{\infty} \beta^{t}\left\{s_{j t} u\left(c_{j 1 t}^{s}, c_{j 2 t}^{s}, n_{j t}^{s}\right)+i_{j t} u\left(c_{j 1 t}^{i}, c_{j 2 t}^{i}, n_{j t}^{i}\right)+r_{j t} u\left(c_{j 1 t}^{r}, c_{j 2 t}^{r}, n_{j t}^{r}\right)\right\} .
$$

Here, $s_{j t}, i_{j t}$ and $r_{j t}$ denote the measure of family members who are susceptible, infected and recovered.

The budget constraint for high-income households, expressed in units of local currency, is

$$
\begin{gathered}
X_{t} b_{h t+1}^{*}+P_{1 t}\left(s_{h t} c_{h 1 t}^{s}+i_{h t} c_{h 1 t}^{i}+r_{h t} c_{h 1 t}^{r}\right)+P_{2 t}\left(s_{h t} c_{h 2 t}^{s}+i_{h t} c_{h 2 t}^{i}+r_{h t} c_{h 2 t}^{r}\right) \\
=w_{h t}\left(s_{h t} n_{h t}^{s}+i_{h t} n_{h t}^{i}+r_{h t} n_{h t}^{r}\right)+\left(1+r^{*}\right) X_{t} b_{h t}^{*}+\Gamma_{h t} .
\end{gathered}
$$


Here $b_{h t}^{*}$ denotes the household's holdings of a foreign currency bond and $\Gamma_{h t}$ is government lump-sum transfers. ${ }^{4}$ Recall that $X_{t}$ is the spot exchange rate which is equal to one. There is no sign restriction on $b_{h t}^{*}$. The household is subject to the non-Ponzi scheme condition,

$$
\lim _{t \rightarrow \infty} \frac{b_{h t+1}^{*}}{\left(1+r^{*}\right)^{t}}=0 .
$$

There is no expectation operator in this expression because the household has a continuum of members, so, the law of large numbers applies.

The nominal budget constraint for low-income households is,

$$
\begin{aligned}
& P_{1 t}\left(s_{l t} c_{l 1 t}^{s}+i_{l t} c_{l 1 t}^{i}+r_{l t} c_{l 1 t}^{r}\right)+P_{2 t}\left(s_{l t} c_{l 2 t}^{s}+i_{l t} c_{l 2 t}^{i}+r_{l t} c_{l 2 t}^{r}\right) \\
& \quad=w_{l t}\left(s_{l t} n_{l t}^{s}+i_{l t} n_{l t}^{i}+r_{l t} n_{l t}^{r}\right)+\Gamma_{l t},
\end{aligned}
$$

where $\Gamma_{l t}$ is government lump-sum transfers.

The household takes into account the probability of its susceptible members becoming infected when consuming or working. The household takes as given the total number of high- and low-income people infected in the economy, as well as aggregate consumption and hours worked.

The variables $\lambda_{j s t}, \lambda_{j i t}, \lambda_{j r t}$ and $\lambda_{j \tau t}$ denote the Lagrange multipliers associated with Eqs. (4), (5), (6) and (8). The variable $\lambda_{j b t}$ denotes the Lagrange multiplier associated with the budget constraint for household type $j$.

The first-order conditions for the consumption of good one and two by people with health status $j$ are:

$$
\begin{gathered}
\left(1-\epsilon_{t}^{c}\right) \frac{1-\eta}{c_{j 1 t}^{x}-\bar{c}}=P_{1 t} \lambda_{b j t}-\lambda_{j \tau t}\left(1-\epsilon_{t}^{\tau}\right) \pi_{1}\left(I_{h t} C_{h 1 t}^{i}+I_{l t} C_{l 1 t}^{i}\right) \Im_{j}, \\
\left(1-\epsilon_{t}^{c}\right) \frac{\eta}{c_{j 2 t}^{x}}=P_{2 t} \lambda_{b j t}-\lambda_{j \tau t}\left(1-\epsilon_{t}^{\tau}\right) \pi_{2}\left(I_{h t} C_{h 2 t}^{i}+I_{l t} C_{l 2 t}^{i}\right) \Im_{j} .
\end{gathered}
$$

Here, the indicator function $\mathfrak{\Im}_{j}$ takes the value one if a person of type $j$ is susceptible and zero otherwise.

The first-order condition for the labor supply of high-income susceptible people is:

$$
\theta n_{h t}^{s}=w_{h t} \lambda_{h b t}+\lambda_{h \tau t} \pi_{j 3}\left(1-\epsilon_{t}^{\tau}\right) I_{h t} N_{h t}^{i} \mathfrak{\Im}_{h} .
$$

Recall that the first-order conditions for hours worked by low-income people do not hold because of sticky wages. Hours worked by low-income people are demand determined. To simplify, we assume that all low-income people supply the same hours of work independently of their health status.

\footnotetext{
${ }^{4}$ To simplify the notation, we omit the profits from the budget constraint since these are always zero in equilibrium.
} 
The first-order conditions with respect to $s_{j t+1}, i_{j t+1}, r_{j t+1}$ and $\tau_{j t}$ are:

$$
\begin{aligned}
m & +\left(1-\epsilon_{t+1}^{c}\right)(1-\eta) \log \left(c_{j 1 t+1}^{s}-\bar{c}\right)+\left(1-\epsilon_{t+1}^{c}\right) \eta \log \left(c_{j 2 t+1}^{s}\right) \\
& -\frac{\theta}{2}\left(n_{j t+1}^{s}\right)^{2}+\lambda_{j \tau t+1}\left(1-\epsilon_{t+1}^{\tau}\right)\left[\pi_{1} c_{j 1 t+1}^{s}\left(I_{j t+1} C_{j 1 t+1}^{i}+I_{j t+1} C_{j 1 t+1}^{i}\right)\right. \\
& +\pi_{2} c_{j 2 t+1}^{s}\left(I_{j t+1} C_{j 2 t+1}^{i}+I_{j t+1} C_{j 2 t+1}^{i}\right) \\
& \left.+\pi_{j 3} n_{j t+1}^{s} I_{j t+1} N_{j t+1}^{i}+\pi_{4}\left(I_{j t+1}+I_{j t+1}\right)\right] \\
& +\lambda_{j b t+1}\left[w_{j t+1} n_{j t+1}^{s}-P_{1 t+1} c_{j 1 t+1}^{s}-P_{2 t+1} c_{j 2 t+1}^{s}\right]-\lambda_{j s t} / \beta+\lambda_{j s t+1}=0, \\
m+ & \left(1-\epsilon_{t+1}^{c}\right)(1-\eta) \log \left(c_{j 1 t+1}^{i}-\bar{c}\right)+\left(1-\epsilon_{t+1}^{c}\right) \eta \log \left(c_{j 2 t+1}^{i}\right) \\
& -\frac{\theta}{2}\left(n_{j t+1}^{i}\right)^{2}+\lambda_{j b t+1}\left[w_{j t+1} n_{j t+1}^{i}-P_{1 t+1} c_{j 1 t+1}^{i}-P_{2 t+1} c_{j 2 t+1}^{i}\right] \\
& -\lambda_{j i t} / \beta+\lambda_{j i t+1}\left(1-\pi_{r j}-\pi_{j d}\right)+\lambda_{j r t+1} \pi_{r j}=0, \\
m+ & \left(1-\epsilon_{t+1}^{c}\right)(1-\eta) \log \left(c_{j 1 t+1}^{r}-\bar{c}\right)+\left(1-\epsilon_{t+1}^{c}\right) \eta \log \left(c_{j 2 t+1}^{r}\right) \\
& -\frac{\theta}{2}\left(n_{j t+1}^{r}\right)^{2}+\lambda_{j b t+1}\left[w_{j t+1} n_{j t+1}^{r}-P_{1 t+1} c_{j 1 t+1}^{r}-P_{2 t+1} c_{j 2 t+1}^{r}\right] \\
& -\lambda_{j r t} / \beta+\lambda_{j r t+1}=0, \\
& -\lambda_{j \tau t}-\lambda_{j s t}+\lambda_{j i t}=0 .
\end{aligned}
$$

\subsection{Government Budget Constraint}

We model the various income stabilization programs implemented in the USA and in other countries as follows. The government makes positive lump-sum transfers to low-income workers $\left(\Gamma_{l t}>0\right)$ until period $T$. These transfers are financed by issuing government debt, $b_{g t}$ which yields an interest rate $r^{*}$. In every period after time $T$, the government levies lump-sum taxes on high-income workers $\left(\Gamma_{h t}<0\right)$ to finance interest on the accumulated government debt. The flow government budget constraint is given by

$$
\begin{gathered}
b_{g t+1}=\Gamma_{l t}\left(S_{l t}+I_{l t}+R_{l t}\right)+\Gamma_{h t}\left(S_{h t}+I_{h t}+R_{h t}\right)+\left(1+r^{*}\right) b_{g t}, \\
\Gamma_{h t}=0 \text { for } t<T, \Gamma_{l t}=0 \text { for } t \geq T, \\
\Gamma_{h t}\left(S_{h t}+I_{h t}+R_{h t}\right)=-r^{*} b_{g t} \text { for } t \geq T,
\end{gathered}
$$

where $S_{j t}, I_{j t}$ and $R_{j t}$ denote the aggregate level of susceptibles, infected and recovered people in group $j$. This formulation is consistent with a run up in government debt during the epidemic. Equation (13) implies that the level of government debt remains stable after period $T$. Equations (11), (12) and (13) satisfy the non-Ponzi scheme condition 


$$
\lim _{t \rightarrow \infty} \frac{b_{g t+1}}{\left(1+r^{*}\right)^{t}}=0 .
$$

Ricardian equivalence holds for high-income households who can borrow and lend at the same rate as the government. So, the precise path of $\Gamma_{h t}$ does not affect consumption of high-income households.

\subsection{Equilibrium Conditions}

In equilibrium, households maximize their utility, firms maximize profits, and the government budget constraint holds. The markets for goods one and two clear,

$$
\begin{aligned}
& Y_{1 t}=\left(S_{h t} c_{h 1 t}^{s}+I_{h t} c_{h 1 t}^{i}+R_{h t} c_{h 1 t}^{r}\right)+\left(S_{l t} c_{l 1 t}^{s}+I_{l t} c_{l 1 t}^{i}+R_{l t} c_{l 1 t}^{r}\right), \\
& b_{h t+1}^{*}+\left(S_{l t} c_{l 2 t}^{s}+I_{l t} c_{l 2 t}^{i}+R_{l t} c_{l 2 t}^{r}\right)+\left(S_{h t} c_{h 2 t}^{s}+I_{h t} c_{h 2 t}^{i}+R_{h t} c_{h 2 t}^{r}\right)=Y_{2 t}+\left(1+r^{*}\right) b_{h t}^{*} .
\end{aligned}
$$

The labor market for high- and low-income people clear:

$$
\begin{aligned}
& N_{l t}=S_{l t} n_{l t}^{s}+I_{l t} n_{l t}^{i}+R_{l t} n_{l t}^{r}, \\
& N_{h t}=S_{h t} n_{h t}^{s}+I_{h t} n_{h t}^{i}+R_{h t} n_{h t}^{r} .
\end{aligned}
$$

The fraction of people in household type $j$ who are susceptible, infected and recovered is the same as the corresponding fractions in the population:

$$
s_{j t}=S_{j t}, i_{j t}=I_{j t}, \text { and } r_{j t}=R_{j t} .
$$

Aggregate consumption $\left(C_{t}\right)$ and hours worked $\left(N_{t}\right)$ are given by

$$
\begin{aligned}
C_{t}= & P_{1 t}\left[\left(S_{h t} c_{h 1 t}^{s}+I_{h t} c_{h 1 t}^{i}+R_{h t} c_{h 1 t}^{r}\right)+\left(S_{l t} c_{l 1 t}^{s}+I_{l t} c_{l 1 t}^{i}+R_{l t} c_{l 1 t}^{r}\right)\right] \\
& {\left[\left(S_{h t} c_{h 2 t}^{s}+I_{h t} c_{h 2 t}^{i}+R_{h t} c_{h 2 t}^{r}\right)+\left(S_{l t} c_{l 2 t}^{s}+I_{l t} c_{l 2 t}^{i}+R_{l t} c_{l 2 t}^{r}\right)\right], } \\
N_{t}= & \left(S_{l t} n_{l t}^{s}+I_{l t} n_{l t}^{i}+R_{l t} n_{l t}^{r}\right)+\left(S_{h t} n_{h t}^{s}+I_{h t} n_{h t}^{i}+R_{h t} n_{h t}^{r}\right) .
\end{aligned}
$$

In the Technical Appendix, we provide a list of the equations that define the equilibrium.

\section{Quantitative Analysis}

In this section, we describe the model calibration and discuss the model's quantitative properties. We then discuss how containment policies and fiscal transfers impacted inequality in life and death.

\subsection{Model Calibration}

We set the weekly discount factor $\beta$ to $0.98^{1 / 52}$. We choose $\theta$ so that weekly per capita hours worked are equal to 28 , the average hours worked in the USA according to the Bureau of Labor Statistics 2018 time-use survey. We set $\eta=1 / 2$, which implies 
that the share of good one in total consumption expenditures is roughly 50 percent (see Table 3 in Burstein, Eichenbaum and Rebelo (2005)). ${ }^{5}$ The constant in the utility function, $m$, is chosen so that the weighted average value of a statistical life is 3.5 million. ${ }^{6}$ This value is in the range discussed by Kniesner and Viscusi (2019).

We set the share of high-income workers in the labor force to 18 percent. The subsistence level, $\bar{c}$, is chosen so that the share of high-skill workers in the total wage bill is 38 percent. These shares are estimated by combining data from the Bureau of Labor Statistics on the distribution of employment across sectors and the share of high-skill workers in each of these sectors reported by Jaimovich et al. (2020). These authors define high-skill workers in a given industry as workers whose wage exceeds the average wage of college graduates in that industry.

We choose bond holdings in the initial steady state so that average household net worth is equal to $\$ 68,000$, the estimate produced by the US Census for 2010. Since low-income families have zero bond holdings and high-income households represent 18 percent of the population, bond holdings for high-income households are $\$ 68,000 / 0.18=\$ 380,000$. We set $A_{l}=A_{h}=A$ and choose $A$ so that per capita income is $\$ 58,000$ in the pre-epidemic steady state.

Consistent with the evidence in Drefahl et al. (2020), we assume that the mortality rate is roughly 40 percent higher for low-income people than for high-income people. We obtain this estimate by averaging the case fatality rates for men and women reported in Table 3 of Drefahl et al. (2020). In the last tercile of the income distribution, the average mortality rate across men and women is $(0.76+0.26) / 2=0.51$. The analogue number for the second to last tercile is $(0.51-0.01) / 2=0.25$. The average of the latter two numbers is roughly 0.4 , i.e., 40 percent. This evidence is based on Swedish data. We presume that the difference in mortality rates for low- and high-income people are larger in the USA because of the high incidence of comorbidity among poor people and the absence of a universal health-care system. So, our calibration provides a conservative estimate of the role of preexisting inequality in COVID mortality rates.

We set the four parameters that control recovery and death to satisfy four conditions. First, consistent with the evidence in Drefahl et al. (2020) for households in the last tercile of the income distribution, the case fatality rate for low-income households, $\pi_{l d} /\left(\pi_{l d}+\pi_{l r}\right)$, is 0.5 percent. Second, $\pi_{l d} / \pi_{h d}=1.4$. Third, the average time to recovery or death for high-income workers $1 /\left(\pi_{h d}+\pi_{h r}\right)$ is two weeks. Fourth, the average time to recovery or death for low-income workers $1 /\left(\pi_{l d}+\pi_{l r}\right)$ is also two weeks. We obtain the following parameter values: $\pi_{l d}=0.0025, \pi_{h d}=0.0018$, $\pi_{l r}=0.4975$ and $\pi_{h r}=0.4982$.

We set the initial seed of infection in January $2020(\varepsilon)$ to 0.001 . To fit the data on spending and employment, we choose the five parameters $\pi_{1}, \pi_{2}, \pi_{l 3}, \pi_{h 3}$ and $\pi_{4}$ so that the model matches five features of the data: the peak-to-trough

\footnotetext{
5 This is a conservative estimate of the importance of nontradable goods because it abstracts from distribution costs associated with tradable goods.

6 The underlying value of life implied by our calibration for low- and high-income individuals is 2 and 10 million dollars, respectively.
}

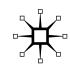


declines in consumption and hours for the two groups, as well as the "Merkel scenario." By the latter we mean that in the model eventually 60 percent of the population is infected in the absence of containment or actions by households to reduce the chances of getting infected (see Eichenbaum et al. 2021 for a discussion). These requirements imply that: (i) infections through work are about 20 times more likely for low-income people than for high-income people and (ii) consumption of good one is 5 percent more contagious than consumption of good two. The resulting parameters of the transmission function are: $\pi_{1}=7.4040 \times 10^{-9}, \pi_{2}=1.1457 \times 10^{-7}, \pi_{h 3}=8.3779 \times 10^{-4}, \pi_{l 3}=5.2498 \times 10^{-4}$ and $\pi_{4}=0.3743$ (see section $\mathrm{C}$ in the Technical Appendix for more details).

Recall that the term $1-\epsilon_{t}^{\tau}$ captures the effect on infection rates of seasonality and private sector reorganization. We choose the time path for $\epsilon_{t}^{\tau}$ so that the model can capture the fact that spending recovered in the 3rd quarter without a corresponding surge in the number of COVID deaths. As a result, we assume that $1-\epsilon_{t}^{\tau}$ falls gradually until it declines by 70 percent between the middle and the end of April.

The term $\epsilon_{t}^{c}$ captures government-imposed containment measures. We choose the level and time path for $\epsilon_{t}^{c}$ with two objectives in mind. First, we want the model to be consistent with the mid-March upsurge of workplace closings in the USA reported by Oxford University's Coronavirus government response tracker. Second, we want the model to be consistent with troughs for consumption and employment of different groups while not overshooting the expansion that occurred in the 3rd quarter. These considerations led us to chose a value of $\epsilon_{t}^{c}$ equal to 30 percent from midMarch on.

Congress passed the Coronavirus Aid, Relief, and Economic Security (CARES) Act on March 27, 2020. Under this law, the US government distributed 267 billion dollars stimulus payments to lower-income households (Garner et al. 2020). This value implies a transfer per low-income household of $267,000 /(260 \times 0.82)$, where 260 is the number of people 16 and older in the USA, measured in millions, and 0.82 is the share of low-income workers in the population. Low-income workers received payments from the CARES act in a lump-sum manner and chose to smooth out the use of those funds over the time. This assumption is consistent with findings in Cox et al. (2020) who argue that transfers associated with stimulus programs can explain the disproportionate increase in liquid balances for low-income people. These balances were spent over time in a way that smoothed consumption. To mimic the resulting consumption pattern in our model, we assume that per capita government transfers to low-income people were on average roughly $\$ 50$ a week for half a year, starting in mid-April. So, in the model the government effectively smooths consumption of low-income households over time.

Finally, we model people's expectations as follows. The epidemic starts in the first week of January but people do not take it into account in their choices of consumption and labor until mid-March. So, all economic variables remain at their steady-state values until mid-March. But people's health status is evolving according to Eqs. (4), (5), (6), (7) and (8). In mid-March, people become aware of the epidemic as well as the path for government transfers to low-income workers, taxes on high-income workers, containment measures and changes in transmission probabilities associated with business reorganization and seasonality. This assumption is 

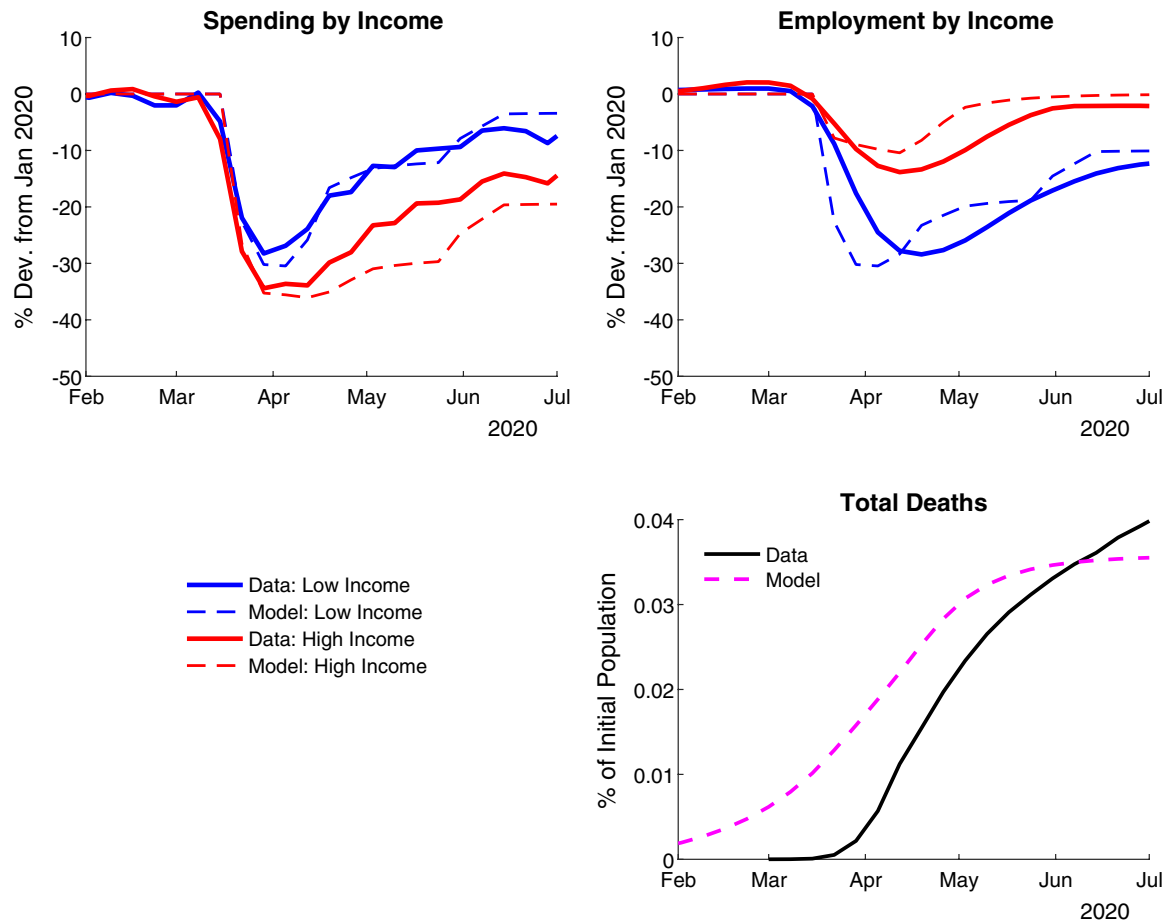

Fig. 4 Spending, Employment and Deaths

consistent with the patterns of searches for the word "COVID" in Google trends. 7 The number of searches prior to March relative to the peak number of searches during the epidemic is less than one percent. The number of searches rose dramatically in the middle of March 2020.

\subsection{Quantitative Properties of the Model}

We focus on the performance of the model in the first sample (from March to July 2020) for two reasons. First, our model abstracts from the possibility of vaccinations and of substantial improvements in treatments. By the fall it became increasingly clear that vaccinations and more effective treatments were likely to arrive soon. This information is likely to have affected people's behavior in ways that our simple model does not capture. Second, the results of the November presidential election is likely to have affected people's expectations about fiscal policy. This effect is likely to have changed people's behavior, particularly that of low-income people, in ways that our model abstracts from.

7 See https://trends.google.com/trends/explore?date=today $\% 205-y \&$ geo=US\&q=COVID . 
Recall that, for tractability, our model has only two types of people. To map the data into this framework, we convert Chetty et al. (2020)'s three income categories into two categories: high income (the top quartile) and low income (the weighted average of the three bottom quartiles). Figure 4 displays income and spending for these two groups as well as total COVID deaths. The red and blue solid (dotted) lines correspond to the high- and low-income group in the data (model), respectively.

This figure shows that our model captures the key qualitative features of the data emphasized in the introduction. First, economic activity troughs in the spring of 2020 and then partially recovers in the summer. Second, the spending by highincome people falls by in percentage terms more than that of low-income people. Third, employment of high-income people falls in percentage terms by less than that of low-income people. Fourth, consumption of high-income people falls by more than employment, so that their income is smoother than their consumption.

In our model, the initial sharp decline in economic activity is fuelled by people's realization in March that there is an ongoing epidemic. The behavior of highincome people is governed by two key considerations. First, they are much less prone to becoming infected at work than low-income people. Second, they have a higher value of life than low-income people which makes them more sensitive to the dangers of becoming infected through market activity. Taken together, these considerations imply that employment falls by less for high-income people than for low-income people. High-income people cut their consumption by more than lowincome people. This result partially reflects the fact that high-income people have access to financial markets, which they use to increase their savings. ${ }^{8}$

The behavior of low-income people is governed by the following considerations. Wages in the nontradable good sector are sticky, so employment is demand determined. Both high- and low-income people cut back on all forms of consumption. Recall that nontradable goods are more infectious than tradable goods, so, high-income people cut back on their consumption of nontradable goods relative to tradable goods by a large amount. Low-income people are closer to the subsistence level, $\bar{c}$, so they reduce their consumption of nontradable goods by less than tradable goods. Since high-income people represent the bulk of spending in both categories, their behavior dominates and there is a disproportionate decline in the demand for nontradable goods. The result is a disproportionately large decline in the employment of low-income people.

The model is consistent with the partial recovery in economic activity during the summer. This recovery is fueled by the assumed drop in infection rates during this period, the phasing out of containment and the implementation of government transfers.

Finally, according to Fig. 4, the model succeeds in accounting for the total number of deaths during the first wave of the epidemic.

\footnotetext{
${ }^{8}$ In the data, savings also increased for low-income people. This increase primarily reflected the pattern of government transfers and consumption smoothing behavior, see Cox et al. (2020).
} 

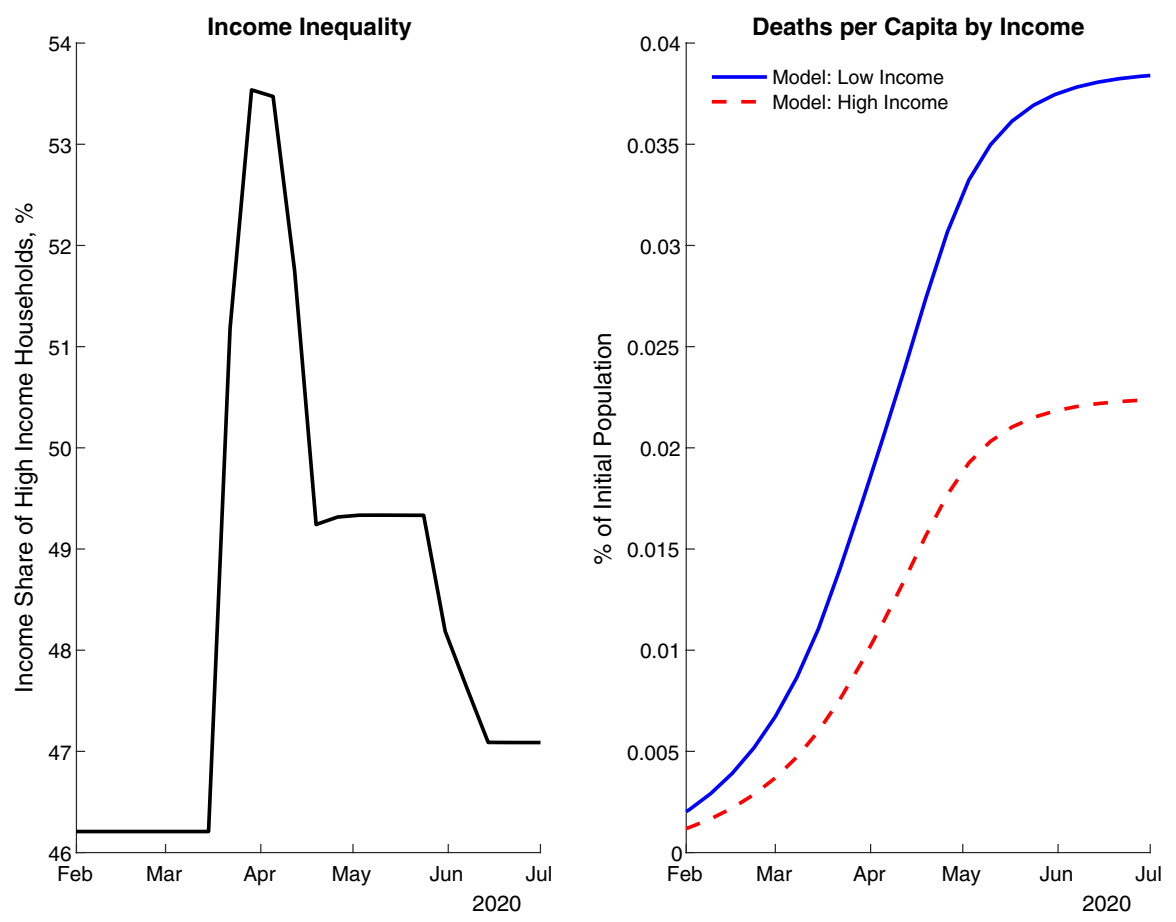

Fig. 5 Income Inequality and Deaths

\section{The impact of $\overline{\mathbf{c}}$}

To quantify the impact of the subsistence level $\bar{c}$, we resolve the model setting $\bar{c}$ to zero. Consistent with the above intuition, in the model with $\bar{c}=0$ the peakto-trough fall in spending is similar for low- and high-income people. So, this version of the model is inconsistent with key facts about consumption documented by Chetty et al. (2020). Since spending in nontradable goods falls by more in the model with $\bar{c}=0$, so too does employment in the nontradable sector. This effect moves the model's implications for employment of low-income people away from the data.

\section{The impact of nominal rigidities}

To quantify the impact of nominal rigidities, we resolve the model assuming that wages are fully flexible. Under this assumption the price of nontradable goods is no longer constant. The model's ability to account for the Chetty et al. (2020) facts does not depend sensitively on the assumption of sticky wages. However, the model's quantitative performance is somewhat worse. The key impact of flexible wages is that the nontradable prices goods increases by about 25 percent between February and April before declining.

\subsection{Inequality in Life and Death}

In this subsection, we analyze the model's implications for inequality in life and death. First, we discuss the dynamics of income inequality and COVID deaths implied by the 


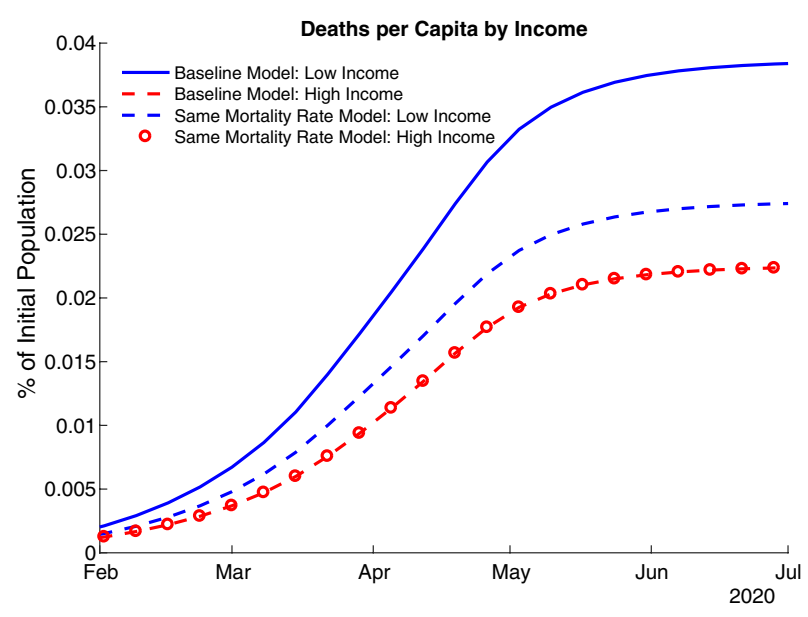

Fig. 6 Income Inequality and Deaths

model. Second, we ask whether the model can account for the empirical correlation across US states between preexisting inequality and cumulative COVID deaths.

Figure 5 shows that at the beginning of the epidemic, high-income people account for 18 percent of the population and 46 percent of total income. Their share of income is substantially higher at the peak of the epidemic in April. This result reflects the sharp relative decline in employment of low-income people and the presence of sticky wages. Consistent with this intuition, much of the inequality wanes as the economy partially recovers in the summer. In this precise sense, the model captures the rise in inequality induced by the epidemic.

The second panel of Fig. 5 displays COVID mortality rates for high- and lowincome people. The model is consistent with the unequal health impact of the epidemic. This inequality reflects two forces. The first force is preexisting inequality in comorbidity rates and access to quality health care. This inequality would have led to a higher death toll among low-income people, regardless of the economic impact of COVID. The second force is the unequal impact of the COVID recession on different types of people. Low-income people are more likely to become infected at work. In addition, they spend a higher fraction of their income on goods whose consumption is associated with higher infection rates. Taken together, these considerations imply that their health is disproportionately impacted by the epidemic.

To isolate the effect of preexisting inequality in comorbidity rates and access to quality health care, we solve the model assuming that the case fatality rate is the same for high- and low-income people $\left(\pi_{l d}=\pi_{h d}\right)$. Figure 6 displays the cumulative mortality rates in this version of the model as well as in the benchmark model. Two key results emerge. First, the death rate among low-income people would have been 30 percent lower if they had the same case fatality rate as high-income people. So, the model implies that preexisting inequality in access to quality health care is a powerful force generating inequality in death. Broadly speaking, this finding is consistent with our empirical findings summarized in Sect. 2 about the link between preexisting inequality and higher mortality rates across countries and US states. 


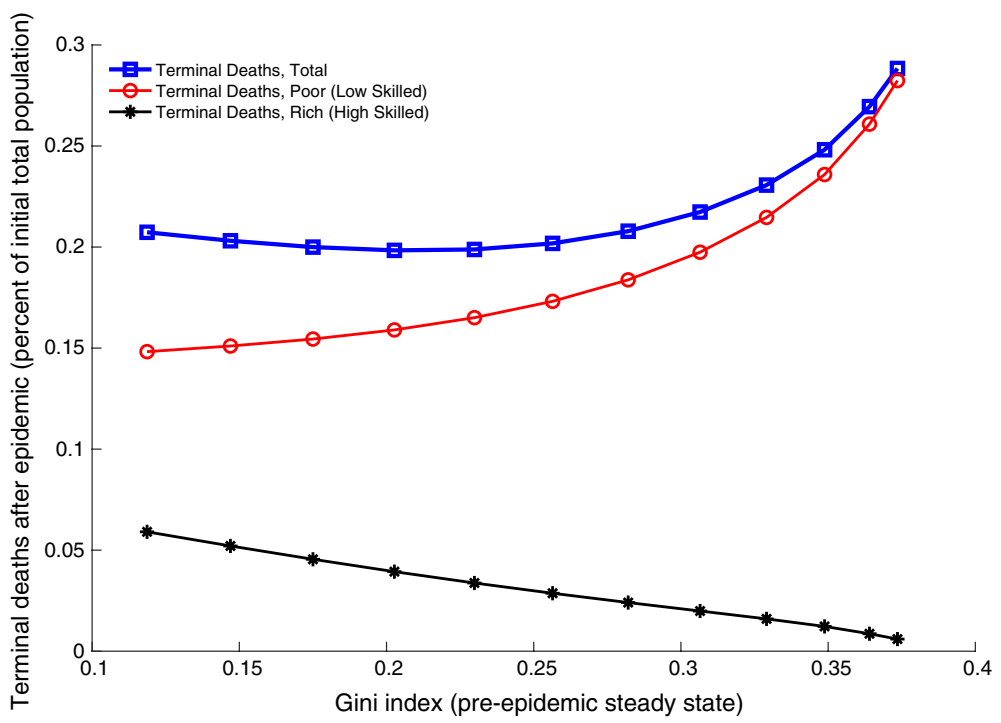

Fig. 7 Inequality in Life and Death

Second, even when $\pi_{l d}=\pi_{h d}$, the COVID mortality rate would have been 23 percent higher for low-income people versus high-income people ( 0.0027 versus 0.0022 percent). The reason is that low-income people work in jobs that expose them to a higher probability of infection. The latter result is consistent with the health literature cited above as well as the economic literature (e.g., Kaplan et al. 2020).

We now turn to the striking statistical correlation across US states between preCOVID income inequality and COVID deaths. To study whether our model can account for this pattern, we solve it for different values of $s_{h}$, the fraction of highskill households in the economy. To isolate the impact of pre-COVID income inequality we recalibrate $A_{l}$ so that the relative price of nontradables is constant across economies. We also maintain the transfers received by low-income households at the level of $\$ 1,200$ used in our baseline calibration. For each value of $s_{h}$, we compute the Gini coefficient in the economy's pre-COVID steady state as well as the total number of COVID deaths of high- and low-income people.

It is well known that the Gini coefficient is sensitive to the share of income received by a set of very wealthy people that represent a small fraction of the population. Building on Atkinson (2007), Alvaredo (2010) shows that if the very wealth receive a fraction $S$ of total income and are an infinitesimal fraction of the population, the Gini coefficient, $G$, is approximately equal to $G^{*}(1-S)+S$, where $G^{*}$ is the Gini coefficient for the rest of the population. In our baseline calibration the Gini coefficient is 0.3 . According to Piketty et al. (2017), the top 1 percent income earners in the USA received 22 percent of total income in 2015. Our model abstracts from the presence of these types of people. The Gini coefficient for the USA in 2019 is 0.48 . Using the Atkinson-Alvaredo approximation to correct for the presence of the top 1 percent income earners yields a Gini coefficient of roughly 0.3 . 
Figure 7 plots cumulative COVID deaths for high- and low-income people as well as total COVID deaths for different Gini coefficient values in our model. As background for interpreting the figure, note that increasing $s_{h}$, i.e., raising the fraction of the population that has high income, reduces the Gini coefficient. ${ }^{9}$ According to the graph, a smaller Gini coefficient is associated with a larger number of high-income people dying. This property is driven by the fact that there are more high-income people. The COVID mortality rate for high-income person declines slowly as $s_{h}$ falls.

A smaller Gini coefficient is associated with fewer low-income people dying. This property reflects two forces that work in the same direction. First, there are fewer low-income people in economies with low Gini coefficients. Second, in lowGini economies, wages of low-income people are higher so the value of their life is higher. So, low-income people reduce their labor supply and consumption of highcontact goods. As a result their COVID-related mortality falls.

The relation between the Gini coefficient and total deaths depends on whether low- or high-income households dominate. For an empirically plausible range around a corrected Gini coefficient of 0.3 , the behavior of low-income households dominates so that less inequality is associated with fewer overall deaths. So, viewed overall, the model accounts for the positive association between COVID deaths and income inequality documented in our empirical work.

\subsection{Policy Interventions}

Our model embodies two important policies implemented during the first phase of the epidemic: containment and fiscal transfers to low-income people. We use the model to assess how these policies impacted inequality in life and death.

The pink lines in column one and two of Fig. 8 show how income inequality and deaths per capita would have evolved in the absence of transfers to low-income people. Two key results emerge. First, the rise in income inequality generated by the epidemic would have been much more persistent absent fiscal transfers. The reason is that transfers increase the demand for nontradable goods and employment of low-income people. Second, the mortality rates would have been slightly lower for both income groups had there been no transfers. Absent transfers economic activity would have been lower, resulting in lower infection rates. Overall, transfers reduced income inequality and stimulated economic activity without having a large impact on the death toll of the epidemic. So, according to our model there is not much of a trade-off between using transfers to reduce COVID-related income inequality and the adverse health outcomes of higher economic activity.

The green lines in column one and two of Fig. 8 shows how income inequality and deaths per capita would have evolved in the absence of containment. Both groups consume more in this scenario. Since wages are sticky in the nontradable good sector and the demand for nontradable goods is higher, there is more employment for lowincome workers. The spending effects are particularly strong in the midsummer since

\footnotetext{
9 The Gini index reflects two forces: i) the relative income of rich and poor people and ii) the number of rich and poor people. There would be perfect equality, if everyone was poor or everyone was rich. In our parameterized model a larger share of the population becoming rich reduces the Gini index.
} 

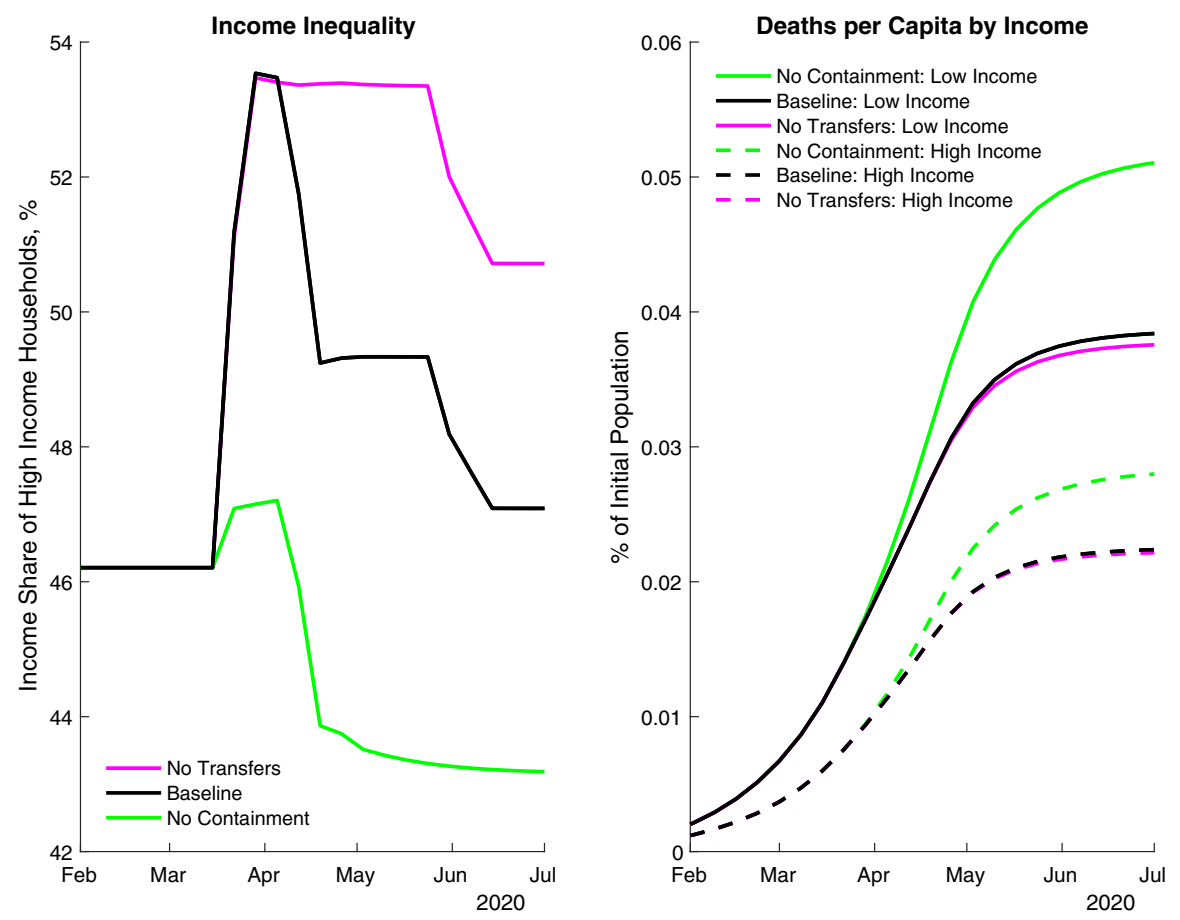

Fig. 8 Sensitivity of Income Inequality and Deaths

low-income workers continue to receive fiscal transfers and there is no containment. As a result, income inequality temporarily dips below its pre-epidemic level.

In sum, containment disproportionately reduced the employment and income of lowincome workers, magnifying income inequality. At the same time, containment dramatically reduced mortality rates for all people. This reduction was roughly 31 percent for lowincome workers and 27 percent for high-income workers. So containment per se greatly increases income inequality but saved many lives of both high- and low-income people.

\section{Conclusion}

In this paper, we develop a model that allows us to analyze why poor people suffered disproportionately from the COVID epidemic. While simple, our model accounts for key aspects of the COVID recession in the USA. First, economic activity steeply declined at the onset of the epidemic and then partially recovered in the summer. Second, employment fell disproportionately more and consumer spending disproportionately less for low-income people, relative to high-income people. Finally, consumer spending by highincome people fell, in percentage terms, by substantially more than their employment.

For the USA, our model suggests that preexisting inequality in health conditions was a key driver of the disproportionately high toll suffered by poor people. But 
inequality in the nature of occupations contributed a great deal as well. Neither of these forces could have been effectively countered once the epidemic began. As a result, the poor paid a terrible price.

\section{Appendix A Equilibrium Equations}

The model has the following 54 endogenous variables:

$$
\begin{aligned}
& P_{1 t}, P_{2 t}, C_{t}, N_{t}, w_{l t}, w_{h t}, \tau_{l t}, \tau_{h t}, b_{h t}^{*}, \\
& s_{h t}, i_{h t}, r_{h t}, d_{h t}, s_{l t}, i_{l t}, r_{l t}, d_{l t}, n_{h t}^{s}, n_{h t}^{i}, \\
& n_{h t}^{r}, n_{l t}^{s}, n_{l t}^{i}, n_{l t}^{r}, c_{h 1 t}^{s}, c_{h 1 t}^{i}, c_{h 1 t}^{r}, c_{h 2 t}^{s}, b_{t}^{g o v} \\
& c_{h 2 t}^{i}, c_{h 2 t}^{r}, c_{l 1 t}^{s}, c_{l 1 t}^{i}, c_{l 1 t}^{r}, c_{l 2 t}^{s}, c_{l 2 t}^{i}, c_{l 2 t}^{r}, \lambda_{l b t}, \lambda_{h b t}, \\
& \lambda_{l \tau t}, \lambda_{h \tau t}, \lambda_{l s t}, \lambda_{h s t}, \lambda_{l i t}, \lambda_{h i t}, \lambda_{l r t}, \lambda_{h r t}, C_{h t}, C_{l t}, \\
& N_{l t}, N_{h t}, \Gamma_{h t}, \Gamma_{l t}, U_{l t}, U_{h t}
\end{aligned}
$$

Exogenous variables:

$$
\epsilon_{t}^{\tau}, \epsilon_{t}^{c}, \epsilon_{t}^{\Gamma},
$$

where $\epsilon_{t}^{\Gamma}$ is an exogenous variable shifting government transfers to low-skilled people.

We have the following 54 nonlinear equilibrium equations which we solve using a gradient-based two-point boundary-value algorithm. See the replication files available on the authors' websites for details.

Market clearing good 1:

$$
\left(s_{h t} c_{h 1 t}^{s}+i_{h t} c_{h 1 t}^{i}+r_{h t} c_{h 1 t}^{r}\right)+\left(s_{l t} c_{l 1 t}^{s}+i_{l t} c_{l 1 t}^{i}+r_{l t} c_{l 1 t}^{r}\right)=A_{l}\left(s_{l t} n_{l t}^{s}+i_{l t} n_{l t}^{i}+r_{l t} n_{l t}^{r}\right) .
$$

Budget constraint high-skill household:

$$
\begin{gathered}
P_{2 t} b_{h t+1}^{*}+P_{1 t}\left(s_{h t} c_{h 1 t}^{s}+i_{h t} c_{h 1 t}^{i}+r_{h t} c_{h 1 t}^{r}\right)+P_{2 t}\left(s_{h t} c_{h 2 t}^{s}+i_{h t} c_{h 2 t}^{i}+r_{h t} c_{h 2 t}^{r}\right) \\
=w_{h t}\left(s_{h t} n_{h t}^{s}+i_{h t} n_{h t}^{i}+r_{h t} n_{h t}^{r}\right)+\left(1+r^{*}\right) P_{2 t} b_{h t}^{*}+\Gamma_{h t} .
\end{gathered}
$$

Budget constraint low-skill household:

$$
\begin{aligned}
& P_{1 t}\left(s_{l t} c_{l 1 t}^{s}+i_{l t} c_{l 1 t}^{i}+r_{l t} c_{l 1 t}^{r}\right)+P_{2 t}\left(s_{l t} c_{l 2 t}^{s}+i_{l t} c_{l 2 t}^{i}+r_{l t} c_{l 2 t}^{r}\right) \\
= & w_{l t}\left(s_{l t} n_{l t}^{s}+i_{l t} n_{l t}^{i}+r_{l t} n_{l t}^{r}\right)+\Gamma_{l t} .
\end{aligned}
$$

Good 2 is the numeraire, so:

$$
P_{2 t}=1 \text {. }
$$

Labor is paid its marginal product:

$$
\begin{aligned}
& w_{l t}=P_{1 t} A_{l}, \\
& w_{h t}=P_{2 t} A_{h} .
\end{aligned}
$$


Aggregate consumption and labor:

$$
\begin{aligned}
C_{t}= & P_{1 t}\left[\left(s_{h t} c_{h 1 t}^{s}+i_{h t} c_{h 1 t}^{i}+r_{h t} c_{h 1 t}^{r}\right)+\left(s_{l t} c_{l 1 t}^{s}+i_{l t} c_{l 1 t}^{i}+r_{l t} c_{l 1 t}^{r}\right)\right] \\
& +P_{2 t}\left[\left(s_{h t} c_{h 2 t}^{s}+i_{h t} c_{h 2 t}^{i}+r_{h t} c_{h 2 t}^{r}\right)+\left(s_{l t} c_{l 2 t}^{s}+i_{l t} c_{l 2 t}^{i}+r_{l t} c_{l 2 t}^{r}\right)\right], \\
N_{t}= & \left(s_{l t} n_{l t}^{s}+i_{l t} n_{l t}^{i}+r_{l t} n_{l t}^{r}\right)+\left(s_{h t} n_{h t}^{s}+i_{h t} n_{h t}^{i}+r_{h t} n_{h t}^{r}\right) .
\end{aligned}
$$

First-order condition (FOC) foreign bond:

$$
\lambda_{h b t}=\left(1+r^{*}\right) \beta \frac{P_{2 t+1}}{P_{2 t}} \lambda_{h b t+1} .
$$

Population dynamics:

$$
\begin{aligned}
\tau_{l t}=(1 & \left.-\epsilon_{t}^{\tau}\right)\left[\pi_{1} s_{l t} c_{l 1 t}^{s}\left(i_{h t} c_{h 1 t}^{i}+i_{l t} c_{l 1 t}^{i}\right)+\pi_{2} s_{l t} c_{l 2 t}^{s}\left(i_{h t} c_{h 2 t}^{i}+i_{l t} c_{l 2 t}^{i}\right)\right. \\
& \left.+\pi_{l 3} s_{l t} n_{l t}^{s} i_{l t} n_{l t}^{i}+\pi_{4} s_{l t}\left(i_{h t}+i_{l t}\right)\right], \\
\tau_{h t}=(1 & \left.-\epsilon_{t}^{\tau}\right)\left[\pi_{1} s_{h t} c_{h 1 t}^{s}\left(i_{h t} c_{h 1 t}^{i}+i_{l t} c_{l 1 t}^{i}\right)+\pi_{2} s_{h t} c_{h 2 t}^{s}\left(i_{h t} c_{h 2 t}^{i}+i_{l t} c_{l 2 t}^{i}\right)\right. \\
& \left.+\pi_{h 3} s_{h t} n_{h t}^{s} i_{h t} n_{h t}^{i}+\pi_{4} s_{h t}\left(i_{h t}+i_{l t}\right)\right] .
\end{aligned}
$$

For $j \in\{l, h\}:$

$$
\begin{aligned}
s_{j t+1}=s_{j t} & -\tau_{j t}, \\
i_{j t+1}=(1 & \left.-\pi_{j r}-\pi_{d j}\right) i_{j t}+\tau_{j t}, \\
r_{j t+1}=r_{j t} & +\pi_{j r} i_{j t}, \\
d_{j t+1}=d_{j t} & +\pi_{d j} i_{j t}, \\
m & +\left(1-\epsilon_{t+1}^{c}\right)(1-\eta) \log \left(c_{j 1 t+1}^{s}-\bar{c}\right)+\left(1-\epsilon_{t+1}^{c}\right) \eta \log \left(c_{j 2 t+1}^{s}\right) \\
& -\frac{\theta}{2}\left(n_{j t+1}^{s}\right)^{2}+\lambda_{j \tau t+1}\left(1-\epsilon_{t+1}^{\tau}\right)\left[\pi_{1} c_{j 1 t+1}^{s}\left(i_{h t+1} c_{h 1 t+1}^{i}+i_{l t+1} c_{l 1 t+1}^{i}\right)\right. \\
& +\pi_{2} c_{j 2 t+1}^{s}\left(i_{h t+1} c_{h 2 t+1}^{i}+i_{l t+1} c_{l 2 t+1}^{i}\right) \\
& \left.+\pi_{j 3} n_{j t+1}^{s} i_{j t+1} n_{j t+1}^{i}+\pi_{4}\left(i_{h t+1}+i_{l t+1}\right)\right] \\
& +\lambda_{j b t+1}\left[w_{j t+1} n_{j t+1}^{s}-P_{1 t+1} c_{j 1 t+1}^{s}-P_{2 t+1} c_{j 2 t+1}^{s}\right]-\lambda_{j s t} / \beta+\lambda_{j s t+1}=0, \\
m+ & \left(1-\epsilon_{t+1}^{c}\right)(1-\eta) \log \left(c_{j 1 t+1}^{i}-\bar{c}\right)+\left(1-\epsilon_{t+1}^{c}\right) \eta \log \left(c_{j 2 t+1}^{i}\right) \\
& -\frac{\theta}{2}\left(n_{j t+1}^{i}\right)^{2}+\lambda_{j b t+1}\left[w_{j t+1} n_{j t+1}^{i}-P_{1 t+1} c_{j 1 t+1}^{i}-P_{2 t+1} c_{j 2 t+1}^{i}\right] \\
& -\lambda_{j i t} / \beta+\lambda_{j i t+1}\left(1-\pi_{r j}-\pi_{j d}\right)+\lambda_{j r t+1} \pi_{r j}=0, \\
m+ & \left(1-\epsilon_{t+1}^{c}\right)(1-\eta) \log \left(c_{j 1 t+1}^{r}-\bar{c}\right)+\left(1-\epsilon_{t+1}^{c}\right) \eta \log \left(c_{j 2 t+1}^{r}\right) \\
& -\frac{\theta}{2}\left(n_{j t+1}^{r}\right)^{2}+\lambda_{j b t+1}\left[w_{j t+1} n_{j t+1}^{r}-P_{1 t+1} c_{j 1 t+1}^{r}-P_{2 t+1} c_{j 2 t+1}^{r}\right] \\
& -\lambda_{j r t} / \beta+\lambda_{j r t+1}=0, \\
& -\lambda_{j \tau t}-\lambda_{j s t}+\lambda_{j i t}=0 . \\
& \\
&
\end{aligned}
$$


Consumption first-order conditions (FOCs), susceptibles:

$$
\begin{gathered}
\left(1-\epsilon_{t}^{c}\right) \frac{1-\eta}{c_{j 1 t}^{s}-\bar{c}}=P_{1 t} \lambda_{j b t}-\lambda_{j \tau t}\left(1-\epsilon_{t}^{\tau}\right) \pi_{1}\left(i_{h t} c_{h 1 t}^{i}+i_{l t} c_{l 1 t}^{i}\right), \\
\left(1-\epsilon_{t}^{c}\right) \frac{\eta}{c_{j 2 t}^{s}}=P_{2 t} \lambda_{j b t}-\lambda_{j \tau t}\left(1-\epsilon_{t}^{\tau}\right) \pi_{2}\left(i_{h t} c_{h 2 t}^{i}+i_{l t} c_{l 2 t}^{i}\right)
\end{gathered}
$$

Labor supply high skilled, susceptibles:

$$
\theta n_{h t}^{s}=w_{h t} \lambda_{h b t}+\lambda_{h \tau t} \pi_{h 3}\left(1-\epsilon_{t}^{\tau}\right) i_{h t} n_{h t}^{i} .
$$

Sticky wages, low skilled:

$$
w_{l t}=w_{l}
$$

Further FOCs:

$$
\begin{aligned}
& \left(1-\epsilon_{t}^{c}\right) \frac{1-\eta}{c_{j 1 t}^{i}-\bar{c}}=P_{1 t} \lambda_{j b t}, \\
& \left(1-\epsilon_{t}^{c}\right) \frac{\eta}{c_{j 2 t}^{i}}=P_{2 t} \lambda_{j b t}, \\
& \theta n_{h t}^{i}=w_{h t} \lambda_{h b t}, \\
& n_{l t}^{i}=n_{l t}^{s}, \\
& \left(1-\epsilon_{t}^{c}\right) \frac{1-\eta}{c_{j 1 t}^{r}-\bar{c}}=P_{1 t} \lambda_{j b t}, \\
& \left(1-\epsilon_{t}^{c}\right) \frac{\eta}{c_{j 2 t}^{r}}=P_{2 t} \lambda_{j b t}, \\
& \theta n_{h t}^{r}=w_{h t} \lambda_{h b t}, \\
& n_{l t}^{r}=n_{l t}^{s} .
\end{aligned}
$$

Government transfers to low-skill people:

$$
\Gamma_{l t}=\epsilon_{t}^{\Gamma},
$$

where $\epsilon_{t}^{\Gamma}$ is an exogenous shifter of transfers to low-skill people.

Government budget with international borrowing by the government and lumpsum tax rule:

$$
\begin{aligned}
b_{t+1}^{g o v}-\Gamma_{h t}\left(s_{h t}+i_{h t}+r_{h t}\right) & =\Gamma_{l t}\left(s_{l t}+i_{l t}+r_{l t}\right)+\left(1+r^{*}\right) b_{t}^{g o v}, \\
\Gamma_{h t} & =0 \text { for } t=1 \ldots 104, \\
\Gamma_{h t}\left(s_{h t}+i_{h t}+r_{h t}\right) & =-r^{*} b_{t}^{g o v} \text { for } t>104 .
\end{aligned}
$$

Total consumption expenditures and total labor supplied by high- and low-skill people: 


$$
\begin{aligned}
C_{h t} & =P_{1 t}\left(s_{h t} c_{h 1 t}^{s}+i_{h t} c_{h 1 t}^{i}+r_{h t} c_{h 1 t}^{r}\right)+P_{2 t}\left(s_{h t} c_{h 2 t}^{s}+i_{h t} c_{h 2 t}^{i}+r_{h t} c_{h 2 t}^{r}\right), \\
C_{l t} & =P_{1 t}\left(s_{l t} c_{l 1 t}^{s}+i_{l t} c_{l 1 t}^{i}+r_{l t} c_{l 1 t}^{r}\right)+P_{2 t}\left(s_{l t} c_{l 2 t}^{s}+i_{l t} c_{l 2 t}^{i}+r_{l t} c_{l 2 t}^{r}\right), \\
N_{l t} & =s_{l t} n_{l t}^{s}+i_{l t} n_{l t}^{i}+r_{l t} n_{l t}^{r}, \\
N_{h t} & =s_{h t} n_{h t}^{s}+i_{h t} n_{h t}^{i}+r_{h t} n_{h t}^{r} .
\end{aligned}
$$

Utility:

$$
\begin{aligned}
U_{j t}= & s_{j t}\left[m+\left(1-\epsilon_{t}^{c}\right)(1-\eta) \log \left(c_{j 1 t}^{s}-\bar{c}\right)+\left(1-\epsilon_{t}^{c}\right) \eta \log \left(c_{j 2 t}^{s}\right)-\frac{\theta}{2}\left(n_{j t}^{s}\right)^{2}\right] \\
& +i_{j t}\left[m+\left(1-\epsilon_{t}^{c}\right)(1-\eta) \log \left(c_{j 1 t}^{i}-\bar{c}\right)+\left(1-\epsilon_{t}^{c}\right) \eta \log \left(c_{j 2 t}^{i}\right)-\frac{\theta}{2}\left(n_{j t}^{i}\right)^{2}\right] \\
& +r_{j t}\left[m+\left(1-\epsilon_{t}^{c}\right)(1-\eta) \log \left(c_{j 1 t}^{r}-\bar{c}\right)+\left(1-\epsilon_{t}^{c}\right) \eta \log \left(c_{j 2 t}^{r}\right)-\frac{\theta}{2}\left(n_{j t}^{r}\right)^{2}\right] \\
& +\beta U_{j t+1} .
\end{aligned}
$$

By Walras' law, the market clearing condition for good 2 is redundant and hence not included in the above system of equilibrium equations:

$$
\begin{aligned}
& b_{h t+1}^{*}+\left(s_{l t} c_{l 2 t}^{s}+i_{l t} c_{l 2 t}^{i}+r_{l l} c_{l 2 t}^{r}\right)+\left(s_{h t} c_{h 2 t}^{s}+i_{h t} c_{h 2 t}^{i}+r_{h t} c_{h 2 t}^{r}\right) \\
= & A_{h}\left(s_{h t} n_{h t}^{s}+i_{h t} n_{h t}^{i}+r_{h t} n_{h t}^{r}\right)+\left(1+r^{*}\right) b_{h t}^{*} .
\end{aligned}
$$

\section{Appendix B Pre-Epidemic Steady state}

Assuming no containment and no transfers in the pre-epidemic steady state, we obtain:

$$
\begin{aligned}
s_{l} & =1-s_{h}, \\
r^{*} & =\frac{1}{\beta}-1, \\
P_{2} & =1 .
\end{aligned}
$$

After repeated substitutions, we obtain the following system of seven core steadystate equations with seven unknowns: 


$$
\begin{aligned}
& s_{h} c_{h 1}^{s}+s_{l} c_{l 1}^{s}=A_{l}\left(s_{l} n_{l}^{s}\right), \\
& P_{1} s_{h} c_{h 1}^{s}+P_{2} s_{h} c_{h 2}^{s}=P_{2} A_{h}\left(s_{h} n_{h}^{s}\right)+r^{*} P_{2} b_{h}^{*}, \\
& P_{1}\left(s_{l} c_{l 1}^{s}\right)+P_{2}\left(s_{l} c_{l 2}^{s}\right)=P_{1} A_{l}\left(s_{l} n_{l}^{s}\right), \\
& \theta n_{h}^{s}=A_{h} \frac{1-\eta}{c_{h 1}^{s}-\bar{c}} \frac{P_{2}}{P_{1}} \\
& \theta n_{l}^{s}=A_{l} \frac{1-\eta}{c_{l 1}^{s}-\bar{c}} \\
& \frac{1-\eta}{c_{h 1}^{s}-\bar{c}} \frac{P_{2}}{P_{1}}=\frac{\eta}{c_{h 2}^{s}} \\
& \frac{1-\eta}{c_{l 1}^{s}-\bar{c}}=P_{1} \frac{\eta}{P_{2} c_{l 2}^{s}} .
\end{aligned}
$$

Substituting out yields the following three equations:

$$
\begin{aligned}
& \frac{\eta}{1-\eta}\left(c_{h 1}^{s}-\bar{c}\right)=\frac{P_{2}}{P_{1}}\left(\frac{A_{h}^{2}}{\theta} \frac{1-\eta}{c_{h 1}^{s}-\bar{c}} \frac{P_{2}}{P_{1}}\right)-c_{h 1}^{s}+\frac{r^{*} P_{2} b_{h}^{*}}{s_{h} P_{1}}, \\
& s_{l} c_{l 1}^{s}=A_{l} s_{l}\left[\frac{A_{l}}{\theta} \frac{1-\eta}{c_{l 1}^{s}-\bar{c}}\right]-s_{h} c_{h 1}^{s}, \\
& c_{l 1}^{s}+\frac{\eta}{1-\eta}\left(c_{l 1}^{s}-\bar{c}\right)=\frac{A_{l}^{2}}{\theta} \frac{(1-\eta)}{c_{l 1}^{s}-\bar{c}} .
\end{aligned}
$$

We solve these equations numerically for $c_{l 1}^{s}, c_{h 1}^{s}$ and $P_{1}$. Using this information, we calculate the remaining steady-state variables: 


$$
\begin{aligned}
w_{l} & =P_{1} A_{l}, \\
n_{l}^{s} & =w_{l} \frac{1}{\theta P_{1}} \frac{1-\eta}{c_{l 1}^{s}-\bar{c}}, \\
n_{h}^{s} & =\frac{P_{2} A_{h}}{\theta P_{1}} \frac{1-\eta}{c_{h 1}^{s}-\bar{c}}, \\
c_{l 2}^{s} & =\frac{\eta}{\frac{P_{2}}{P_{1}} \frac{1-\eta}{c_{l 1}^{s}-\bar{c}}}, \\
c_{h 2}^{s} & =\frac{\eta}{P_{2}} \frac{1-\eta}{P_{1}}, \\
C & =P_{11}\left(s_{h} c_{h 1}^{s}+s_{l} c_{l 1}^{s}\right)+P_{2}\left(s_{h} c_{h 2}^{s}+s_{l} c_{l 2}^{s}\right), \\
N & =s_{l} n_{l}^{s}+n_{h}^{s} s_{h}, \\
\lambda_{b j} & =\frac{1}{P_{1}} \frac{1-\eta}{c_{j 1}^{s}-\bar{c}}, \\
c_{j 1}^{i} & =c_{j 1}^{r}=c_{j 1}^{s}, \\
c_{j 2}^{i} & =c_{j 2}^{r}=c_{j 2}^{s}, \\
n_{j}^{i} & =n_{j}^{r}=n_{j}^{s} .
\end{aligned}
$$

Finally,

$$
\begin{aligned}
& i_{j}=0 \\
& r_{j}=0 \\
& d_{j}=0 \\
& \tau_{j}=0 \\
& \lambda_{j}^{s}=\frac{1}{1 / \beta-1}\left(\begin{array}{c}
m+(1-\eta) \log \left(c_{j 1}^{s}-\bar{c}\right)+\eta \log \left(c_{j 2}^{s}\right) \\
-\frac{\theta}{2}\left(n_{j}^{s}\right)^{2}+\lambda_{b j}\left[w_{j} n_{j}^{s}-P_{1} c_{j 1}^{s}-P_{2} c_{j 2}^{s}\right]
\end{array}\right), \\
& \lambda_{j}^{r}=\frac{1}{1 / \beta-1}\left(\begin{array}{c}
m+(1-\eta) \log \left(c_{j 1}^{r}-\bar{c}\right)+\eta \log \left(c_{j 2}^{r}\right) \\
-\frac{\theta}{2}\left(n_{j}^{r}\right)^{2}+\lambda_{b j}\left[w_{j} n_{j}^{r}-P_{1} c_{j 1}^{r}-P_{2} c_{j 2}^{r}\right]
\end{array}\right), \\
& \lambda_{j}^{i}= \frac{1}{1 / \beta-\left(1-\pi_{r j}-\pi_{j d}\right)}\left(\begin{array}{c}
m+(1-\eta) \log \left(c_{j 1}^{i}-\bar{c}\right)+\eta \log \left(c_{j 2}^{i}\right) \\
-\frac{\theta}{2}\left(n_{j}^{i}\right)^{2}+\lambda_{b j}\left[w_{j} n_{j}^{i}-P_{1} c_{j 1}^{i}-P_{2} c_{j 2}^{i}\right]+\lambda_{j}^{r} \pi_{r j}
\end{array}\right), \\
& \lambda_{j}^{\tau}=\lambda_{j}^{i}-\lambda_{j}^{s} .
\end{aligned}
$$

where $j \in\{h, l\}$. 


$$
\begin{aligned}
C_{h} & =P_{1}\left(s_{h} c_{h 1}^{s}\right)+P_{2}\left(s_{h} c_{h 2}^{s}\right), \\
C_{l} & =P_{1} s_{l} c_{l 1}^{s}+P_{2} s_{l} c_{l 2}^{s}, \\
N_{l} & =s_{l} n_{l}^{s}, \\
N_{h} & =s_{h} n_{h}^{s}, \\
U_{j} & =\frac{1}{1-\beta} s_{j}\left[m+(1-\eta) \log \left(c_{j 1}^{s}-\bar{c}\right)+\eta \log \left(c_{j 2}^{s}\right)-\frac{\theta}{2}\left(n_{j}^{s}\right)^{2}\right] .
\end{aligned}
$$

\section{Appendix C Calibration of transmission parameters}

The parameters of the transmission functions are pinned down as follows:

$$
\begin{aligned}
\tau_{t}=\tau_{l t} & +\tau_{h t}=\pi_{1}\left(s_{l t} c_{l 1 t}^{s}+s_{h t} c_{h 1 t}^{s}\right)\left(i_{h t} c_{h 1 t}^{i}+i_{l t} c_{l 1 t}^{i}\right) \\
& +\pi_{2}\left(s_{l t} c_{l 2 t}^{s}+s_{h t} c_{h 2 t}^{s}\right)\left(i_{h t} c_{h 2 t}^{i}+i_{l t} c_{l 2 t}^{i}\right) \\
& +\left(\pi_{l 3} s_{l t} n_{l t}^{s} i_{l t} n_{l t}^{i}+\pi_{h 3} s_{h t} n_{h t}^{s} i_{h t} n_{h t}^{i}\right)+\pi_{4}\left(s_{l t}+s_{h t}\right)\left(i_{h t}+i_{l t}\right),
\end{aligned}
$$

or

$$
\begin{aligned}
\frac{\tau_{0}}{\left(i_{h 0}+i_{l 0}\right)}= & \frac{\pi_{1}\left(s_{l 0} c_{l 1}^{s}+s_{h 0} c_{h 1}^{s}\right)\left(i_{h 0} c_{h 1}^{i}+i_{l 0} c_{l 1}^{i}\right)+\pi_{2}\left(s_{l 0} c_{l 2}^{s}+s_{h 0} c_{h 2}^{s}\right)\left(i_{h 0} c_{h 2}^{i}+i_{l 0} c_{l 2}^{i}\right)}{\left(i_{h 0}+i_{l 0}\right)} \\
& +\frac{\left(\pi_{l 3} s_{l 0} n_{l}^{s} i_{l 0} n_{l}^{i}+\pi_{h 3} s_{h 0} n_{h}^{s} i_{h 0} n_{h}^{i}\right)+\pi_{4}\left(s_{l 0}+s_{h 0}\right)\left(i_{h 0}+i_{l 0}\right)}{\left(i_{h 0}+i_{l 0}\right)} .
\end{aligned}
$$

Note that:

$$
\begin{aligned}
i_{h 0} & =s_{h} \varepsilon, i_{l 0}=s_{l} \varepsilon, \\
s_{h 0} & =s_{h}-s_{h} \varepsilon, s_{l 0}=s_{l}-s_{l} \varepsilon, \\
1 & =s_{h}+s_{l} .
\end{aligned}
$$

So that

$$
\begin{aligned}
\frac{\tau_{0}}{(1-\varepsilon) \varepsilon}= & \pi_{1}\left(s_{l} c_{l 1}^{s}+s_{h} c_{h 1}^{s}\right)\left(s_{h} c_{h 1}^{i}+s_{l} c_{l 1}^{i}\right)+\pi_{2}\left(s_{l} c_{l 2}^{s}+s_{h} c_{h 2}^{s}\right)\left(s_{h} c_{h 2}^{i}+s_{l} c_{l 2}^{i}\right) \\
& +\left(\pi_{l 3} s_{l} n_{l}^{s} s_{l} n_{l}^{i}+\pi_{h 3} s_{h} n_{h}^{s} s_{h} n_{h}^{i}\right)+\pi_{4} .
\end{aligned}
$$

We impose the following conditions to calibrate the transmission function parameters (see the main text for more details): 


$$
\begin{aligned}
& 1=\frac{\overbrace{\pi_{1}\left(s_{l} c_{l 1}^{s}+s_{h} c_{h 1}^{s}\right)\left(s_{h} c_{h 1}^{i}+s_{l} c_{l 1}^{i}\right)+\pi_{2}\left(s_{l} c_{l 2}^{s}+s_{h} c_{h 2}^{s}\right)\left(s_{h} c_{h 2}^{i}+s_{l} c_{l 2}^{i}\right)}^{1 / 12}}{\frac{\tau_{0}}{(1-\varepsilon) \varepsilon}} \\
& +\underbrace{\frac{\left(\pi_{l 3} s_{l} n_{l}^{s} s_{l} n_{l}^{i}+\pi_{h 3} s_{h} n_{h}^{s} s_{h} n_{h}^{i}\right)}{\frac{\tau_{0}}{(1-\varepsilon) \varepsilon}}}_{5 / 12}+\underbrace{\frac{\pi_{4}}{\frac{\tau_{0}}{(1-\varepsilon) \varepsilon}}}_{6 / 12} \\
& \pi_{l 3} s_{l} n_{l}^{s} s_{l} n_{l}^{i}=20 \times \pi_{h 3} s_{h} n_{h}^{s} s_{h} n_{h}^{i} \\
& \pi_{1}\left(s_{l} c_{l 1}^{s}+s_{h} c_{h 1}^{s}\right)\left(s_{h} c_{h 1}^{i}+s_{l} c_{l 1}^{i}\right)=1.05 \times \pi_{2}\left(s_{l} c_{l 2}^{s}+s_{h} c_{h 2}^{s}\right)\left(s_{h} c_{h 2}^{i}+s_{l} c_{l 2}^{i}\right) \\
& d_{l t}+d_{h t}+r_{l t}+r_{h t}=0.6 \text { for } t \rightarrow \infty \text {. }
\end{aligned}
$$

\section{References}

Abel, J. R., and Deitz, R. 2021. Some Workers Have Been Hit Much Harder than Others by the Pandemic. No. 20210209a. Federal Reserve Bank of New York.

Acemoglu, D., Chernozhukov V., Iván W. and Whinston, M. D. 2020. A Multi-Risk SIR Model with Optimally Targeted Lockdown. No. w27102. National Bureau of Economic Research.

Alon, T. M., Doepke, M., Olmstead-Rumsey J. and Tertilt, M. 2020. The Impact of COVID-19 on Gender Equality. No. w26947. National Bureau of Economic Research.

Alvaredo, F. 2011. A Note on the Relationship Between Top Income Shares and the Gini Coefficient. Economics Letters 110 (3): 274-277.

Alvarez, F. E., Argente D. and Francesco, L. 2021. A Simple Planning Problem for COVID-19 Lockdown, Testing and Tracing. American Economic Review: Insights (forthcoming).

Atkinson, A.B. 2007. Measuring Top Incomes: Methodological Issues. Top Incomes Over the Twentieth Century: A Contrast Between Continental European and English-Speaking Countries 1: 18-42.

Benitez, J., C. Courtemanche, and A. Yelowitz. 2020. Racial and Ethnic Disparities in COVID-19: Evidence from Six Large Cities. Journal of Economics, Race, and Policy 3 (4): 243-261.

Brotherhood, L., Kircher, P., Santos, C. and Michèle T. An Economic Model of the COVID-19 Epidemic: The Importance of Testing and Age-Specific Policies.

Buera, F., Fattal-Jaef, R., Neumeyer, A. and Shin, Y. (2020) The Economic Ripple Effects of COVID19. Unpublished Manuscript. Available at the World Bank Development Policy and COVID-19eSeminar Series.

Burstein, A., M. Eichenbaum, and S. Rebelo. 2005. Large Devaluations and the Real Exchange Rate. Journal of Political Economy 113 (4): 742-784.

Tillmann von, C., Almås, I., Bold, T., Ghisolfi S., Sandefur, J. 2020. The Macroeconomics of Pandemics in Developing Countries: An Application to Uganda, Working Paper 555, Center for Global Development.

Carvalho, V. M., Hansen, S., Ortiz, A., Garcia, J. R., Rodrigo, T., Mora, S. R., Ruiz de Aguirre, P.. 2020. Tracking the COVID-19 Crisis with High-Resolution Transaction Data, BBVA Working Paper 20/06, April .

Cavallo, A. 2020. Inflation with COVID Consumption Baskets, No. w27352. National Bureau of Economic Research.

Center for Disease Control and Prevention Evidence used to Update the List of Underlying Medical Conditions that Increase a Person's Risk of Severe Illness from COVID-19, 2020, https://www.cdc.gov/ coronavirus/2019-ncov/need-extra-precautions/evidence-table.html.

Chen, J.T., and N. Krieger. 2020. Revealing the Unequal Burden of COVID-19 by Income, Race/Ethnicity, and Household Crowding: US County versus Zip Code Analyses. Journal of Public Health Management and Practice 27 (1): S43-S56.

Chetty, R., Friedman, J. N., Hendren, N., Stepner, M., and the Opportunity Insights Team. 2020. How Did COVID-19 and Stabilization Policies Affect Spending and Employment? A New Real-Time Economic Tracker Based on Private Sector Data. 
Cox, N., Ganong, P., Noel, P., Vavra J., Wong, A., Farrell, D., and Fiona, G. 2020. Initial Impacts of the Pandemic on Consumer Behavior: Evidence from Linked Income, Spending, and Savings Data, University of Chicago, Becker Friedman Institute for Economics Working Paper 2020-82.

Crucini, M. J. and O'Flaherty, O. 2020. Stay-at-Home Orders in a Fiscal Union, NBER Working Paper No. 28182, December

Dingel, J. I. and Neiman, B. 2020. How Many Jobs Can be Done at Home?, NBER Working Paper No. 26948, April .

Desmet, K., and Wacziarg, R. 2021. JUE Insight: Understanding Spatial Variation in COVID-19 Cross the United States. Journal of Urban Economics, 103332.

Drefahl, S., M. Wallace, E. Mussino, et al. 2020. A Population-Based Cohort Study of Socio-Demographic Risk Factors for COVID-19 Deaths in Sweden. Nature Communication 11: 5097.

Eichenbaum, Martin S., Sergio Rebelo, and Mathias Trabandt. 2021. The Macroeconomics of Epidemics, Forthcoming. Review of Financial Studies .

Eichenbaum, M. S., Godinho de Matos, M., Lima, F., Rebelo, S., and Trabandt, M. 2020. How do People Respond to Small Probability Events with Large Negative Consequences?, NBER Working Paper No 27998, October.

Engler, P., Pouokam, N., Guzman, D. R., and Yakadina, I. Forthcoming. Fiscal Redistribution and Inequality in the Time of a Pandemic, IMF Working Paper, International Monetary Fund, Washington DC.

Erceg, C.J., D.W. Henderson, A. Levin, and A.T. Levin. 2000. Optimal Monetary Policy with Staggered Wage and Price Contracts. Journal of Monetary Economics 46 (2): 281-313.

Farboodi, M., Jarosch, G., Shimer, R. 2020. Internal and External Effects of Social Distancing in a Pandemic. No. w27059. National Bureau of Economic Research.

Faria-e-Castro, M. 2021. Fiscal Policy During a Pandemic. Journal of Economic Dynamics and Control 125: 104088 .

Garner, T.I., A. Safir, and J. Schild. 2020. Receipt and Use of Stimulus Payments in the Time of the COVID-19 Pandemic. Bureau of Labor Statistics, August: Beyond the Numbers.

Glover, A., Heathcote, J., Krueger, D., and Ríos-Rull, J.-V. 2020. Health versus wealth: On the distributional effects of controlling a pandemic. No. w27046. National Bureau of Economic Research, .

Martín, G.-E. and Niepelt, D. 2020. On the Optimal Lockdown During an Epidemic, Manuscript, Study Center Gerzensee.

Guerrieri, V., Lorenzoni, G., Straub, L., and Werning, I. 2020. Macroeconomic Implications of COVID19: Can Negative Supply Shocks Cause Demand Shortages?. No. w26918. National Bureau of Economic Research,.

Giagheddu, M. and Papetti, A. 2020. The Macroeconomics of Age-Variant Epidemics, manuscript,.

Hacioglu, S., Känzig, R., Surico, P. 2020. The Distributional Impact of the Pandemic, CEPR DP No. 15101.

Hall, R.E., and C.I. Jones. 2007. The Value of Life and the Rise in Health Spending. The Quarterly Journal of Economics 122 (1): 39-72.

Hosseinpoor, A.R., N. Bergen, S. Mendis, S. Harper, E. Verdes, A. Kunst, and S. Chatterji. 2012. Socioeconomic Inequality in the Prevalence of Noncommunicable Diseases in Low-and Middle-Income Countries: Results from the World Health Survey. BMC Public Health 12 (1): 474.

Jaimovich, N., S. Rebelo, A. Wong, and M.B. Zhang. 2020. Trading Up and the Kill Premium. NBER Macroeconomics Annual 34 (1): 285-316.

Jin, J.M., P. Bai, W. He, F. Wu, X.F. Liu, D.M. Han, and J.K. Yang. 2020. Gender Differences in Patients with COVID-19: Focus on Severity and Mortality. Frontiers in Public Health 8: 152.

Jones, Callum J., Thomas Philippon, and Venky Venkateswaran. 2020. Optimal Mitigation Policies in a Pandemic: Social Distancing and Working from Home. No. w26984. National Bureau of Economic Research,.

Kaplan, G., G.L. Violante, and J. Weidner. 2014. The Wealthy Hand-to-Mouth. Brookings Papers on Economic Activity 1: 77-153.

Kaplan, G., B. Moll, and G.L. Violante. 2018. Monetary Policy According to HANK. American Economic Review 108 (3): 697-743.

Kaplan, G., Moll, B., and Violante, G. L. 2020. The Great Lockdown and the Big Stimulus: Tracing the Pandemic Possibility Frontier for the U.S., manuscript, University of Chicago,

Kermack, W.O., and A.G. McKendrick. 1927. A Contribution to the Mathematical Theory of Epidemics. Proceedings of the Royal Society of London, series A 115 (772): 700-721.

Kniesner, T. J., and Viscusi, W. K. 2019. The value of a statistical life. Oxford Research Encyclopedia of Economics and Finance 19-15. 
Krieger, N., P.D. Waterman, and J.T. Chen. 2020. COVID-19 and Overall Mortality Inequities in the Surge in Death Rates by ZIP Code Characteristics: Massachusetts, January 1 to May 19, 2020. American Journal of Public Health 110 (12): 1850-1852.

Krueger, D., Uhlig, H., and Xie, T. 2020. Macroeconomic Dynamics and Reallocation in an Epidemic: Evaluating the Swedish Solution, manuscript, University of Pennsylvania .

Leibovici, F. 2020. Ana Maria Santacreu and Matthew Famiglietti Social Distancing and Contact-Intensive Occupations Manuscript. Louis: Federal Reserve Bank of St.

McLaren, J. 2020. Racial Disparity in COVID-19 Deaths: Seeking Economic Roots with Census data. No. w27407. National Bureau of Economic Research

Merow, C. and Urban, M. 2020. Seasonality and Uncertainty in Global COVID-19 Growth Rates, PNAS, $117(44)$

Piketty, T., Saez, E., and Zucman, G. 2017. Distributional National Accounts: Methods and Estimates for the United States, NBER working paper, December 2016. Updated July.

Piguillem, F., and Shi, L. 2020. Optimal COVID-19 Quarantine and Testing Policies.

Price-Haywood, E.G., J. Burton, D. Fort, and L. Seoane. 2020. Hospitalization and Mortality Among Black Patients and White Patients with COVID-19. New England Journal of Medicine. 382 (26): 2534-2543.

Raifman, M. A., and Raifman, J. R. 2020. Disparities in the Population at Risk of Severe illness from COVID-19 by Race/Ethnicity and Income. American Journal of Preventive Medicine.

Ross, M., and Bateman, N. 2019. Meet the Low-wage Workforce. Metropolitan Policy Program at Brookings.

Rubini, L. 2020. Can Social Distancing Work in Low Income Countries?, manuscript,

Toxvaerd, F. M. O. 2020. Equilibrium social distancing.

Williamson, E.J., A.J. Walker, K. Bhaskaran, et al. 2020. Factors Associated with COVID-19-Related Death using OpenSAFELY. Nature 584: 430-436.

Publisher's Note Springer Nature remains neutral with regard to jurisdictional claims in published maps and institutional affiliations.

Martin S. Eichenbaum is the Charles Moskos Professor of economics and the co-director of the Center for International Economics at Northwestern University. He is a fellow of the American Academy of Arts and Sciences, the Royal Society of Canada and the Econometric Society. He is also a Research Associate of the NBER and an International Fellow of the CD Howe Institute. He currently serves as the co-editor of the NBER Macro Annual. He received a PhD in economics from the University of Minnesota.

Sergio Rebelo is the MUFG Professor of International Finance at the Kellogg School of Management, where he has served as Chair of the Finance Department. Professor Rebelo has published widely in macroeconomics and international finance. His research focuses on the causes of business cycles, the impact of economic policy on economic growth, and the sources of exchange rate fluctuations. He has served as a consultant to the World Bank, the International Monetary Fund, the European Commission, the Board of Governors of the Federal Reserve System, the European Central Bank, the McKinsey Global Institute, the Global Markets Institute at Goldman Sachs, and other organizations. He received his Ph.D. in Economics from the University of Rochester.

Mathias Trabandt holds a Ph.D. in economics from Humboldt University Berlin. He is a Professor of Macroeconomics at the Faculty of Economics and Business at Goethe University in Frankfurt am Main. Earlier in his career, he held positions at the Federal Reserve Board of Governors, European Central Bank, Deutsche Bundesbank and Sveriges Riksbank. Mathias Trabandt's research and teaching interests focus on macroeconomics, monetary economics, public economics, labor economics, international macroeconomics, financial frictions, applied econometrics and epidemics. His research has been published in e.g. the American Economic Journal: Macroeconomics, Econometrica, the Journal of Applied Econometrics, the Journal of Economic Dynamics and Control, the Journal of Economic Perspectives, the Journal of Monetary Economics, the European Economic Review, the American Economic Review (Papers and Proceedings), the Review of Economic Dynamics, the Review of Financial Studies and the Handbook of Monetary Economics. 